\title{
Retrieval of aerosol backscatter and extinction from airborne coherent Doppler wind lidar measurements
}

\author{
F. Chouza ${ }^{1}$, O. Reitebuch ${ }^{1}$, S. Groß ${ }^{1}$, S. Rahm ${ }^{1}$, V. Freudenthaler ${ }^{2}$, C. Toledano ${ }^{3}$, and B. Weinzierl ${ }^{1,2}$ \\ ${ }^{1}$ Deutsches Zentrum für Luft- und Raumfahrt (DLR), Institut für Physik der Atmosphäre, Oberpfaffenhofen, Germany \\ ${ }^{2}$ Ludwig-Maximilians-Universität München (LMU), Meteorologisches Institut, München, Germany \\ ${ }^{3}$ University of Valladolid, Atmospheric Optics Group, Valladolid, Spain \\ Correspondence to: F. Chouza (fernando.chouza@dlr.de)
}

Received: 29 January 2015 - Published in Atmos. Meas. Tech. Discuss.: 18 February 2015

Revised: 9 June 2015 - Accepted: 16 June 2015 - Published: 21 July 2015

\begin{abstract}
A novel method for calibration and quantitative aerosol optical property retrieval from Doppler wind lidars (DWLs) is presented in this work. Due to the strong wavelength dependence of the atmospheric molecular backscatter and the low sensitivity of the coherent DWLs to spectrally broad signals, calibration methods for aerosol lidars cannot be applied to coherent DWLs usually operating at wavelengths between 1.5 and $2 \mu \mathrm{m}$. Instead, concurrent measurements of an airborne DWL at $2 \mu \mathrm{m}$ and the POLIS groundbased aerosol lidar at $532 \mathrm{~nm}$ are used in this work, in combination with sun photometer measurements, for the calibration and retrieval of aerosol backscatter and extinction profiles at $532 \mathrm{~nm}$.

The proposed method was applied to measurements from the SALTRACE experiment in June-July 2013, which aimed at quantifying the aerosol transport and change in aerosol properties from the Sahara desert to the Caribbean. The retrieved backscatter and extinction coefficient profiles from the airborne DWL are within $20 \%$ of POLIS aerosol lidar and CALIPSO satellite measurements. Thus the proposed method extends the capabilities of coherent DWLs to measure profiles of the horizontal and vertical wind towards aerosol backscatter and extinction profiles, which is of high benefit for aerosol transport studies.
\end{abstract}

\section{Introduction}

Mineral dust plays a key role in the climate system. About half of the annually emitted aerosol mass is mineral dust (e.g., Hinds 1999) which disturbs the radiation budget, acts as cloud and ice nuclei and is observed to modify the cloud glaciation process (e.g., Seifert et al., 2010).

The Saharan desert has been identified as the world's largest source of mineral dust (e.g., Mahowald et al., 2005). Saharan dust is regularly transported westwards across the Atlantic Ocean (e.g., Prospero, 1999), covering huge areas of the Atlantic Ocean with the dust-containing Saharan Air Layer (SAL). Despite the progress made during the last years, many key questions about the transport, deposition mechanisms and transformation of the Saharan dust remain unanswered (Ansmann et al., 2011).

To study the aging and modification of Saharan mineral dust during long-range transport from the Sahara across the Atlantic Ocean into the Caribbean and investigate the impact of aged mineral dust on the radiation budget and cloud evolution processes, the Saharan Aerosol Long-range Transport and Aerosol-Cloud-Interaction Experiment (SALTRACE: http://www.pa.op.dlr.de/saltrace) was performed in June/July 2013. SALTRACE was designed as a closure experiment combining a set of ground-based lidar, in situ and sun photometer instruments deployed on Barbados (main SALTRACE supersite), Cape Verde and Puerto Rico with airborne aerosol and wind measurements of the DLR (Deutsches Zentrum für Luft- und Raumfahrt) research aircraft Falcon, satellite observations and model simulations. Altogether 31 research flights were conducted between 10 June and 15 July 2013. For the first time, an airborne $2 \mu \mathrm{m}$ Doppler wind lidar (DWL) was deployed to study the dust transport across the Atlantic Ocean. While airborne DWLs were mainly used in the past for atmospheric dynamical studies providing the horizontal wind vector and turbulence mea- 
surements (Reitebuch, 2012; Weissmann et al., 2005; Smalikho, 2003; Reitebuch et al., 2001), they were also used to obtain qualitative aerosol data (Bou Karam et al., 2008; Schumann et al., 2011; Weinzierl et al., 2012). Quantitative aerosol optical properties derived from airborne coherent DWLs, like backscatter and extinction coefficient, are rarely reported (Menzies and Tratt, 1994).

The calibration of aerosol lidars is usually performed using the Rayleigh molecular backscatter from the stratosphere or the high troposphere (Fernald et al., 1984; Klett, 1985; Böckmann et al., 2004). However, this method is not applicable to a coherent DWL operating at a wavelength of $2 \mu \mathrm{m}$. The main reason for that are the low intensity of the molecular backscatter, caused by the strong dependence of the Rayleigh backscatter intensity on the lidar operation wavelength $\left(P \propto \lambda^{-4}\right)$, and the low sensitivity of the coherent DWLs to spectrally broad signals (Henderson et al., 2005). The latter is a consequence of the DWL's design to match the spectrally narrow aerosol return signal to increase the signalto-noise ratio.

Up to now, different approaches were used to retrieve calibrated atmospheric parameters from coherent lidars which are not suitable to be calibrated using molecular background as a reference. Most of these techniques rely on the use of the return signals from targets with known optical properties, including ground-based hard targets (Menzies and Tratt, 1994), sea surface (Bufton et al., 1983) and ground return (Cutten et al., 2002).

The main problems associated with the calibration of a coherent DWL at ground using calibrated targets (Menzies and Tratt, 1994) are the variability in the optical transmission of the boundary layer, the effect of the turbulence in the heterodyning efficiency, the limitations of the calibration range due to target size restrictions and the necessity of a wellcharacterized system heterodyne efficiency. This last problem is related to practical limitations in the distance at which the target can be placed. For usual distances $(<1 \mathrm{~km})$ the lidar is not operating in far field regime and a correction has to be applied taking into account the heterodyne efficiency function. However, the use of different hard targets such as flame-sprayed aluminium or sandpaper allows the characterization of the system depolarization effects and, through the use of moving targets, of the system response to return signal frequency shifts.

The use of sea and ground returns for the calibration of airborne lidars (Bufton et al., 1983; Cutten et al., 2002) avoids some of the previously described problems at the cost of losing some of the advantages of ground-based targets. The refractive turbulence effects are lower because the pathintegrated turbulence is smaller and the heterodyne efficiency function is not essential for the calibration procedure because the ground or sea surface is normally in the region of far field regime. The use of ground return allows also us to perform a continuous calibration, with the instrument operating in normal measuring conditions. Nevertheless, the optical proper- ties of the ground and sea returns have a higher uncertainty and are highly variable between different locations. In the case of the sea surface, they are affected by the wind and the consequent generation of waves and whitecaps ( $\mathrm{Li}$ et al., 2010), while in the case of the ground return relatively constant optical properties are limited to specific regions.

A third method, developed to calibrate cloud lidars (O'Connor et al., 2004), consists in scaling the backscatter signal to match the derived lidar ratio with the theoretical lidar ratio corresponding to stratocumulus clouds. This requires the presence of homogeneous and well-characterized stratocumulus clouds.

The aim of this paper is to provide an alternative calibration method for coherent DWLs. As the combination of ground-based and airborne lidars is a usual approach for large field campaigns aiming at the characterization of aerosols and its transport (Heintzenberg, 2009; Ansmann et al., 2011), the availability of simultaneous airborne and ground-based measurements opens the possibility to a new DWL calibration method. The proposed method relies on the measurement of the same atmospheric volume by two different lidars: a reference aerosol lidar to which the Klett-Fernald method can be applied and the coherent DWL to be calibrated. Based on simultaneous measurements, calibration constants corresponding to different aerosol types are calculated. Those constants can be then applied to retrieve calibrated backscatter and extinction coefficient profiles from the coherent DWL measurements during other flight periods. With the proposed method, not only can information on horizontal and vertical wind vector and transport of the aerosol layers be derived from the (airborne) DWL but synchronous aerosol backscatter and extinction coefficients can also be retrieved.

The paper is organized as follows. Section 2 provides a brief description of the coherent DWL mounted on the Falcon research aircraft of DLR during SALTRACE and an outline of the acquired signal processing. Section 3 describes the instrumental corrections, calibration and retrieval method. Section 4 gives a description of the measurement sets used for the calibration and validation of the method. Section 5 shows the results of the method applied to parts of the SALTRACE measurement set. Finally, a summary and relevant conclusions are presented in Sect. 6.

\section{Coherent DWL instrument}

\subsection{Instrument description}

The airborne coherent DWL used during SALTRACE is based on an instrument from CLR Photonics (Henderson et al., 1993), today Lockheed Martin Coherent Technologies (LMCT), together with a scanning and acquisition system developed by DLR (Köpp et al., 2004) which provides airborne wind measurement capabilities. The lidar operates at a wavelength of $2.02254 \mu \mathrm{m}$, with a pulse full width at half 
maximum of $400 \mathrm{~ns}$, a pulse energy of $1-2 \mathrm{~mJ}$ and a repetition frequency of $500 \mathrm{~Hz}$. The key system specifications are summarized in Table 1.

The system is composed of three units: first, a transceiver head holding the diode pumped solid-state Tm:LuAG laser, the $10.8 \mathrm{~cm}$ diameter afocal transceiver telescope, the receiver optics and detectors and a double wedge scanner; second, a rack with the laser power supply and the cooling unit; third, another rack that contains the data acquisition and control electronics.

The system is deployed in the DLR Falcon 20 research aircraft in order to provide horizontal and vertical wind profiles as well as backscatter measurements. The transceiver head is mounted above the aircraft optical window pointing downwards to allow the measurement of vertical profiles (Fig. 1). The aircraft window consists of a $400 \mathrm{~mm}$ diameter and $35 \mathrm{~mm}$ thick INFRASIL-302 fused silica window with an antireflection coating which was optimized for an angle of incidence of $10^{\circ}$.

While single wedge scanners are only able to perform conical scans with a fixed off-nadir angle, the double wedge scanner used in this system (Käsler et al., 2010) allows us to perform arbitrary scanning patterns. Typically, for airborne measurements the lidar is operated in two modes: step-stare scanning and nadir pointing. The step-stare scanning mode consists of 24 lines of sight (LOS) $\boldsymbol{I}$ in a conical distribution with an off-nadir angle of $20^{\circ}$ and a staring duration of $1 \mathrm{~s}$ per LOS direction. This configuration allows the measurement of horizontal wind speeds with a horizontal resolution of approximately $6 \mathrm{~km}$, depending on aircraft ground speed. However, when the system is operated in nadir pointing mode, the system LOS is kept fixed downwards pointing, while the accumulation period of $1 \mathrm{~s}$ remains the same as for the scanning mode. The nadir pointing mode allows the system to retrieve vertical wind profiles with a horizontal resolution of $200 \mathrm{~m}$. In order to minimize the horizontal wind projection over $\boldsymbol{I}$ when the system is operating in nadir pointing mode, the transceiver head was mounted with a pitch angle $\theta_{\mathrm{m}}$ of $-2^{\circ}$. Together with a variable deflection provided by the scanner $\theta_{\mathrm{S}}$ (which can be set by the operator during flight), the system can compensate the aircraft pitch angle $\theta_{\mathrm{p}}$ and provide nadir pointing measurements $\boldsymbol{I}=\boldsymbol{n}$.

\subsection{Coherent lidar signal equation}

The following subsection discusses the properties and the analysis steps applied to the signal measured by the DWL in order to obtain a magnitude proportional to the atmospheric backscattered power.

The coherent DWL operation relies on the heterodyning technique. The frequency of the light scattered in the atmosphere, $f_{\mathrm{s}}=f_{0}+f_{\mathrm{D}}$, is affected by the Doppler effect, which introduces a frequency shift $f_{\mathrm{D}}$ to the laser pulse frequency $f_{0}$ proportional to the projection of the relative speed $\mathrm{v}_{\mathrm{LOS}}$ between the laser source and the backscattering aerosols on
Table 1. Key parameters of the DWL.

\begin{tabular}{lll}
\hline Laser & Laser type & Solid-state Tm:LuAG \\
\hline & Operation wavelength & $2.02254 \mu \mathrm{m}$ \\
& Laser energy & $1-2 \mathrm{~mJ}$ \\
& Repetition rate & $500 \mathrm{~Hz}$ \\
& Pulse length & \\
& (full width at half maximum) $)$ & $400 \mathrm{~ns}$ \\
& Frequency offset $\left(f_{\mathrm{IF}}\right)$ & $102 \mathrm{MHz}$ \\
\hline \multirow{2}{*}{ Transceiver } & Telescope type & Off-axis \\
& Telescope diameter & $10.8 \mathrm{~cm}$ \\
& Focal length & Afocal \\
& Beam diameter $\left(1 / e^{2}\right)$ & $8 \mathrm{~cm}$ \\
& Transmitted polarization & Circular \\
& Detected polarization & Co-polarized \\
\hline \multirow{2}{*}{ Scanner } & Type & Double wedge \\
& Material & Fused silica \\
\hline Aircraft window & Material & INFRASIL-302 \\
& Coating & Anti-reflection $\left(10^{\circ}\right)$ \\
& Diameter/thickness & $400 / 35 \mathrm{~mm}$ \\
\hline Data acquisition & Sampling rate & $500 \mathrm{MHz}$ \\
& Resolution & 8 bits \\
& Mode & Single shot acquisition
\end{tabular}

the laser pulse direction, with $f_{\mathrm{D}}=2 \mathrm{v}_{\mathrm{LOS}} f_{0} \mathrm{c}^{-1}$. A positive frequency shift $f_{\mathrm{D}}$ indicates a positive relative speed $\mathrm{v}_{\mathrm{LOS}}$, which, in turn, indicates that the scattering aerosols are moving towards the lidar. For the case of an airborne downward pointing lidar, this sign convention leads to positive relative speeds for upward winds and negative relative speeds for downward winds. The atmospheric backscattered fraction of the outgoing pulse is mixed with a frequency shifted $f_{m}=f_{0}+f_{\mathrm{IF}}$ sample of the same local oscillator (LO) used for seeding the outgoing pulse. As a result, the mixed signal contains one spectral component with a frequency equal to the sum of the atmospheric backscatter frequency and the shifted LO frequency $f_{\mathrm{s}}+f_{m}$ and another component with a frequency equal to the difference of both frequencies $\Delta \mathrm{f}=f_{\mathrm{s}}-f_{m}=f_{\mathrm{D}}+f_{\mathrm{IF}}$. Due to the limited detector bandwidth, only the component with frequency $\Delta f$ can be detected. Knowing the frequency of the LO and the shift applied to the LO $\left(f_{\mathrm{IF}}\right)$, it is possible to calculate the shift on the backscatter due to the Doppler effect.

Several authors (e.g., Sonnenschein and Horrigan, 1971; Frehlich and Kavaya, 1991) describe the coherent DWL in different levels of generality. In this work, we will focus on the received power for the specific case of a monostatic pulsed coherent lidar. For a detector with uniform response, the signal photocurrent generated by the atmospheric backscatter can be written as (Henderson et al., 2005)

$i_{\mathrm{h}}(t)=2 \frac{\eta_{\mathrm{q}} e}{h f_{0}} \sqrt{\eta_{\mathrm{LO}} P_{\mathrm{LO}} \eta_{\mathrm{h}}(t) P_{\mathrm{sd}, \boldsymbol{I}}(t)} \cos (2 \pi \Delta f t+\Delta \theta(t))$,

where $i_{\mathrm{h}}$ is the output current from the detector, $t$ the elapsed time since the laser trigger, $\eta_{\mathrm{q}}$ the quantum efficiency, $e$ the electron charge, $h$ the Planck constant, $f_{0}$ the laser frequency, $\eta_{\mathrm{h}}$ the heterodyne efficiency, $\eta_{\mathrm{LO}}$ the local oscillator trunca- 


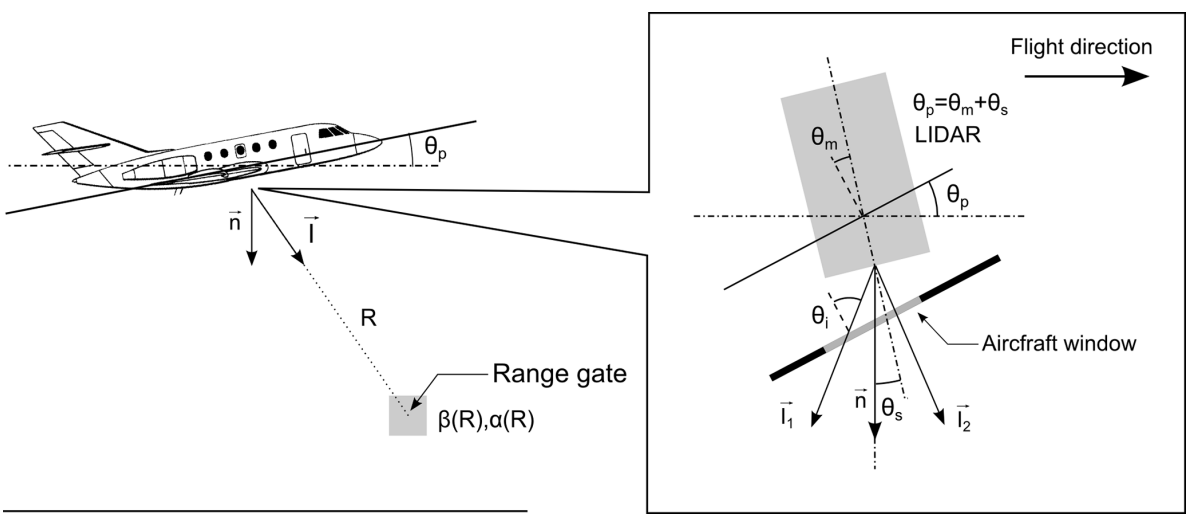

Figure 1. Variables used to calculate the backscattered power from a given range gate, where $R$ is the distance between the range gate and the lidar, $\boldsymbol{I}$ is a unit vector that represents the line of sight (LOS) of the lidar, $\boldsymbol{n}$ is the unit nadir pointing vector, $\beta(R)$ is the backscatter coefficient and $\alpha(R)$ is the extinction coefficient of the sampled atmospheric volume. The zoomed area shows a mounting scheme of the lidar transceiver head. $\boldsymbol{I}_{\mathbf{1}}$ and $\boldsymbol{I}_{\mathbf{2}}$ are examples of the LOS vector when the instrument operates in scanning mode, $\theta_{\mathrm{p}}$ is the aircraft pitch angle, $\theta_{\mathrm{m}}$ is the lidar mounting angle about the transverse aircraft axis, $\theta_{\mathrm{S}}$ is the angle between the transceiver head geometric axis and $\boldsymbol{n}$, and $\theta_{\mathrm{i}}$ is the angle of incidence of the transmitted laser beam on the aircraft window.

tion efficiency, $P_{\mathrm{LO}}$ the $\mathrm{LO}$ power at the detector plane, $P_{\mathrm{sd}, \boldsymbol{I}}$ the atmospheric received power at the detector plane, $\Delta f$ the beat signal frequency and $\Delta \theta$ the signal phase. The heterodyning efficiency reflects the phase and amplitude matching between the backscattered signal and the LO, while the LO truncation efficiency represents the fraction of the LO power applied over the detector area.

The detector output is digitalized by an acquisition board with 8 bit resolution, input impedance $R_{\text {in }}$, gain $G$ and a sampling frequency of $500 \mathrm{MHz}\left(T_{\mathrm{s}}=2 \mathrm{~ns}\right)$. The digitized signal $u_{\mathrm{h}}(\mathrm{n})$ can be written as

$u_{\mathrm{h}}(n)=i_{\mathrm{h}}\left(n T_{\mathrm{s}}\right) R_{\text {in }} G$.

Because the system operates in single shot acquisition mode, the digitized signal $u_{\mathrm{h}}(n)$ for each laser shot is stored during measurement flight. The following processing steps are performed during signal analysis on ground, allowing different instrumental corrections and changes in the temporal and vertical averaging parameters.

In order to obtain range resolved measurements of the backscattered power, the acquired signal is divided in range gates of $N$ samples, with $N=512$. For a range gate at distance $R$, the power spectra $\hat{P}_{\mathrm{S}}(R, k)$ can be calculated from the Fast Fourier Transform using the following expression:

$\hat{P}_{\mathrm{S}}(R, k)=\frac{1}{N}\left|\sum_{n=N_{1}}^{N_{2}} u_{\mathrm{h}}(n) e^{-j \frac{2 \pi k n}{N}}\right|^{2}$,

where $N_{1}=N_{\mathrm{R}}-\frac{N}{2}, N_{2}=N_{\mathrm{R}}+\frac{N}{2}$ and $N_{\mathrm{R}}$ is the sample corresponding to the center of the range gate and it is given by the integer part of $N_{\mathrm{R}}=\left(\frac{2 R}{T_{\mathrm{s}} c}\right)$.
Replacing Eq. (3) with Eqs. (2) and (1) gives

$$
\begin{aligned}
& \hat{P}_{\mathrm{S}}(R, k)= \\
& \frac{1}{N} \mid \sum_{n=N_{1}}^{N_{2}} 2 \frac{\eta_{\mathrm{q}} e}{h f_{0}} R_{\mathrm{in}} G \\
& \left.\sqrt{\eta_{\mathrm{LO}} P_{\mathrm{LO}} \eta_{\mathrm{h}}\left(n T_{\mathrm{s}}\right) P_{\mathrm{sd}, I}\left(n T_{\mathrm{s}}\right)} \cos \left(2 \pi \Delta T_{\mathrm{s}}+\Delta \theta\left(n T_{\mathrm{s}}\right)\right) e^{-j \frac{2 \pi k n}{N}}\right|^{2} .
\end{aligned}
$$

For all the samples belonging to a range gate, the atmospheric return is supposed to be constant: $P_{\mathrm{sd}}\left(n T_{\mathrm{S}}\right)=$ $P_{\text {sd }}(R)$. This approximation leads to the following expression:

$$
\begin{aligned}
& \hat{P}_{\mathrm{S}}(R, k)= \\
& \frac{1}{N}\left(2 \frac{\eta_{\mathrm{q}} e}{h f_{0}} R_{\mathrm{in}} G\right)^{2} \eta_{\mathrm{LO}} P_{\mathrm{LO}} P_{\mathrm{sd}, \boldsymbol{I}}(R) \\
& \left|\sum_{n=N_{1}}^{N_{2}} \sqrt{\eta_{h}\left(n T_{\mathrm{S}}\right)} \cos \left(2 \pi \Delta f n T_{\mathrm{S}}+\Delta \theta\left(n T_{\mathrm{S}}\right)\right) e^{-j \frac{2 \pi k n}{N}}\right|^{2} .
\end{aligned}
$$

Equation (5) represents the backscatter power spectrum of a given range gate for a single shot. Because the received backscatter power $\hat{P}_{\mathrm{S}}(R, k)$ is subject to large amplitude variations between different shots due to speckle effect (Fig. 2a), the power spectrums of many shots are averaged in order to reduce its influence

$$
\left\langle\hat{P}_{S}(R, k)\right\rangle=\frac{1}{\mathrm{I}} \sum_{i=1}^{\mathrm{I}} \hat{P}_{\mathrm{S}, i}(R, k),
$$

where $\hat{P}_{\mathrm{S}, \mathrm{i}}(R, k)$ is the power spectrum of a range gate at distance $R$ corresponding to the shot $i$ and $I$ is the number of averaged shots, which is typically 500 corresponding to 
the temporal average over $1 \mathrm{~s}$. Figure $2 \mathrm{~b}$ illustrates the exponential probability density distribution corresponding to the received power of a ground return range gate for 500 shots.

Finally, in order to estimate the backscattered power for the averaged range gates, the summation of the power spectra components around the spectral maximum is performed. For the sake of simplicity, the noise affecting the system was omitted from the previous equations. During the processing, the noise floor is subtracted from the averaged power spectra before estimating the backscattered power.

The expected value for the backscatter power corresponding to the averaged range gates is calculated through the integration of the average backscatter power spectrum:

$\langle P(R)\rangle=\sum_{k=K_{1}}^{K_{2}}\langle\hat{P}(R, k)\rangle=$

$\frac{1}{N}\left(2 \frac{\eta_{\mathrm{q}} e}{h f_{0}} R_{\mathrm{in}} G\right)^{2} \eta_{\mathrm{LO}} P_{\mathrm{LO}} \eta_{\mathrm{h}}(R) P_{\mathrm{sd}, \boldsymbol{I}}(R)$,

where $K_{1}=k_{\max }-\frac{K}{2}, K_{2}=k_{\max }+\frac{K}{2}, k_{\max }$ is the index corresponding to the maximum of the power spectra and $K$ is the width of the spectral peak corresponding to the backscattered signal. The optimal value for the integration window width $K$ is the one that exactly matches the return pulse spectral width. A shorter integration window will lead to an underestimation of the backscattered power, while a longer integration window increases the estimation error due to the integration of measurement noise. Based on these facts, the integration window width $K$ was set to be 6 (approximately $6 \mathrm{MHz}$ ).

Because each power spectra $\left\langle\hat{P}_{S}(R, k)\right\rangle$ is calculated based on the average of 500 shots and the received power for a single shot follows an exponential probability density function, the mean received power $\langle P(R)\rangle$ can be modeled as a gamma function. If 500 shots are averaged, the resulting average received power relative standard deviation is lower than $5 \%$.

The received atmospheric power $P_{\mathrm{sd}}$, for a given lidar line of sight $\boldsymbol{I}$, can be written as

$P_{\mathrm{sd}, \boldsymbol{I}}(R)=k_{\mathrm{in}, \boldsymbol{I}}(R) E_{\mathrm{T}} \frac{A_{R}}{R^{2}} \frac{\mathrm{c}}{2} \beta(R) T^{2}(R)$,

where $k_{\mathrm{in}, I}(R)$ condenses different instrumental constants, $E_{\mathrm{T}}$ is the mean transmitted energy of the averaged laser pulses, $A_{\mathrm{R}}$ is the telescope area, $c$ is the speed of light, $\beta$ is the backscatter coefficient and $T$ the atmospheric transmission.

Combining all constants in one constant $k_{d}$, replacing Eq. (8) into Eq. (7) and applying a range correction multiplying the backscattered power of each range gate by its squared distance to the lidar, Eq. (7) can be rewritten as

$\langle P(R)\rangle R^{2}=k_{d} E_{\mathrm{T}} k_{\mathrm{in}, I}(R) \eta_{\mathrm{h}}(R) \beta(R) T^{2}(R)$,

where $k_{d}=\frac{1}{N}\left(2 \frac{\eta_{\mathrm{q}} \mathrm{e}}{\mathrm{h} f_{0}} R_{\mathrm{in}} G\right)^{2} \eta_{\mathrm{LO}} P_{\mathrm{LO}} A_{\mathrm{R}} \frac{\mathrm{c}}{2}$.
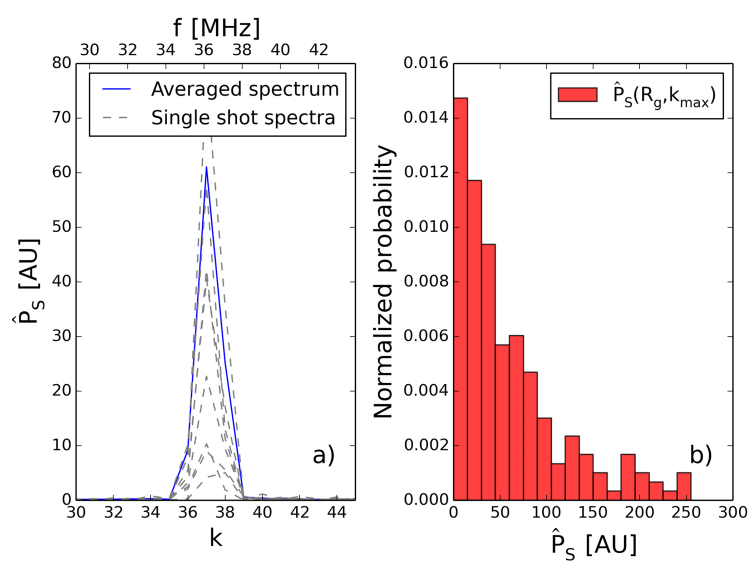

Figure 2. (a) Power spectra of single shots (dashed) and the averaged spectrum of 500 shots (solid) for the range gate corresponding to the ground return $R_{\mathrm{g}}$, an acquisition frequency of $500 \mathrm{MHz}$ and an Fast Fourier Transform length of 512 samples. (b) Exponential distribution for the maximum of the power spectra $\hat{P}_{\mathrm{S}}\left(R_{\mathrm{g}}, k_{\max }\right)$ for 500 shots and the range gate $R_{\mathrm{g}}$.

\section{Calibration and retrieval method}

\subsection{Instrumental corrections}

In order to establish the lidar calibration constants (Sect. 3.3), it is necessary to remove the effect of all the instrumental parameters that change during the measurement, i.e., the laser pulse energy $E_{\mathrm{T}}$, the heterodyne efficiency and the instrumental constants summarized by $k_{\mathrm{in}, \boldsymbol{I}}(R)$.

To remove the dependency of the measured atmospheric signal power on the fluctuation of the laser energy, the rangecorrected signal is divided by the averaged outgoing laser pulse energy $E_{\mathrm{T}}$ corresponding to all the shots averaged to calculate the backscattered power. Although the outgoing pulse energy is not directly measured, a part of each outgoing pulse is mixed with the $\mathrm{LO}$ and the resulting beat signal is stored as frequency reference. The time elapsed between the laser Q-switch trigger and the amplitude maximum of the digitized beat signal corresponds to the pulse build-up time. Based on laboratory measurements (LMCT, personal communication) of the outgoing pulse energy as function of the Q-Switch build-up time (Fig. 3), it is possible to estimate the energy $E_{\mathrm{T}}$ of the outgoing pulses during the lidar operation.

The laser pulse energy-corrected signal is obtained from Eq. (9),

$$
\frac{\langle P(R)\rangle R^{2}}{E_{\mathrm{T}}}=k_{d} k_{\mathrm{in}, I}(R) \eta_{\mathrm{h}}(R) \beta(R) T^{2}(R),
$$

where the instrumental constant $k_{\mathrm{in}, \boldsymbol{I}}(R)$ can be expressed as follows:

$k_{\mathrm{in}, \boldsymbol{I}}(R)=k_{\mathrm{G}} k_{\mathrm{h}}(\Delta f) k_{\theta}(\boldsymbol{I}) k_{\delta}(R)$,

with $k_{\mathrm{G}}$ the acquisition board attenuator, $k_{\mathrm{h}}(\Delta f)$ the system gain as a function of the backscattered signal frequency $\Delta f$, 


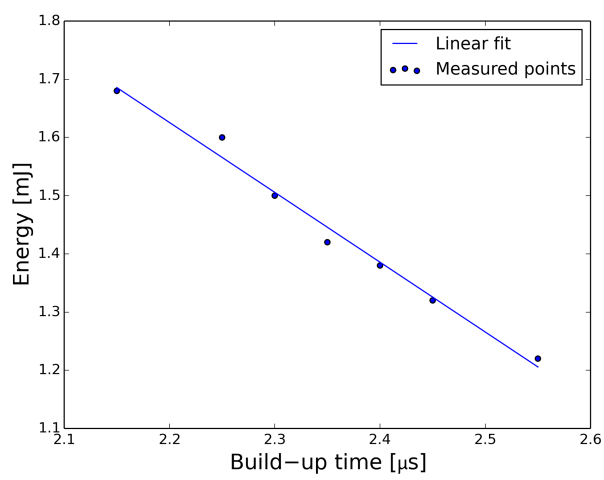

Figure 3. Measured and interpolated pulse energy as a function of the build-up time.

$k_{\theta}(\boldsymbol{I})$ the change in the received power as a function of the line of sight angle of incidence on the aircraft window $\theta_{\mathrm{i}}$ (Fig. 1) and $k_{\delta}(R)$ the detector response depending on the depolarization of the backscattered signal.

The effect of the acquisition board attenuator $k_{\mathrm{G}}$ can be calculated based on the values stored by the acquisition software.

To estimate the change in the heterodyne efficiency $\eta_{\mathrm{h}}$ as a function of the range $R$, measurements corresponding to a set of range gates with the same altitude and similar instrumental constants and atmospheric optical properties were used. The measurements, performed during flight periods for which the aircraft was changing its altitude, show the change of the received power as a function of the range gate distance $R$ due to the variation of the heterodyne efficiency in the near field regime (Fig. 4). Due to sampling of the outgoing laser pulse, atmospheric range gates at distances lower than $500 \mathrm{~m}$ are not digitized. For this reason, the proposed method is applicable only if the extinction corresponding to those range gates can be considered 0 or can be estimated from other sources.

Nonetheless, neglecting the turbulence effects and assuming a monostatic afocal untruncated Gaussian beam lidar, the heterodyne efficiency change as a function of the range $R$ can be approximated with the following expression (Henderson et al., 2005):

$\eta_{\mathrm{h}}(R)=\left[1+\left(\frac{\pi \rho^{2}}{\lambda R}\right)^{2}\right]^{-1}$,

where $\rho$ is the $1 / e^{2}$ irradiance beam radius and $\lambda$ the laser wavelength. Based on the specifications presented in Table 1 and Eq. (12), the expected heterodyne efficiency was calculated and compared with the measured one (Fig. 4). It can be seen that the expected heterodyne efficiency is much lower than the measured one, suggesting that some of the assumptions are not applicable for this case. In order to get a practical correction of the heterodyne efficiency the same function was fit to the measured backscatter power, leaving $\pi \rho^{2} / \lambda$ as optimization parameter. The resulting correction function

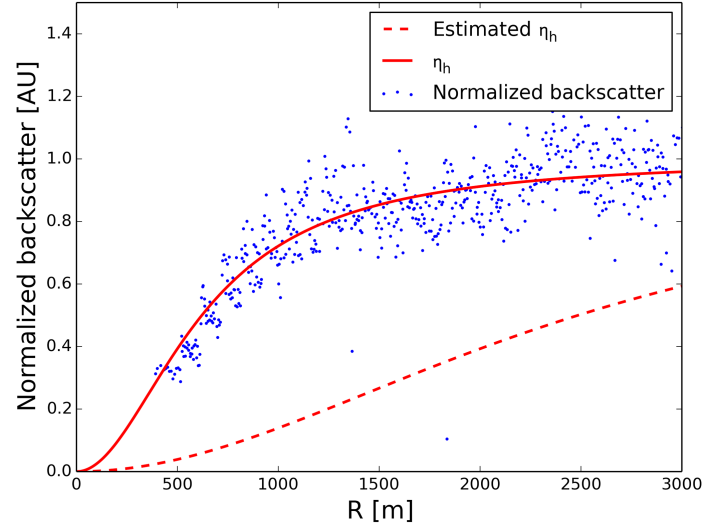

Figure 4. Estimated (red, dashed) and derived (red, solid) heterodyne efficiency $\eta_{\mathrm{h}}$ as a function of range $R$. The normalized backscatter data points (blue dots) correspond to the averaged backscatter power corresponding to range gates at altitudes between 4.5 and $5 \mathrm{~km}$ for a flight altitude between 5.5 and $8 \mathrm{~km}$ during the flights on 22 June and 11 July.

is (Fig. 4)

$\eta_{\mathrm{h}}(R)=\left[1+\left(\frac{621.5}{R}\right)^{2}\right]^{-1}$.

The heterodyne efficiency corrected signal can be obtained from Eqs. (10) and (13):

$$
\frac{\langle P(R)\rangle R^{2}}{E_{\mathrm{T}} \eta_{\mathrm{h}}(R)}=k_{d} k_{\mathrm{in}, I}(R) \beta(R) T^{2}(R) .
$$

According to Eq. (13), for range gates corresponding to ranges $R$ larger than $3500 \mathrm{~m}$, which is the case of the measurements presented in this work (Table 2), the heterodyne efficiency is almost constant (less than $3 \%$ variation) and the system can be considered operating in far field regime with a constant heterodyne efficiency $\eta_{\mathrm{h}}(R)=\eta_{\mathrm{h}}$.

A sample of the received atmospheric backscattered power after applying the energy and attenuator corrections is shown in Fig. 5a. There are also abrupt changes and periodic oscillations present in the atmospheric backscattered power. These steps and oscillations in the received power are due two reasons: the system gain that changes with the backscattered signal frequency $\Delta f$ and the variability of the optical transmission of the transceiver optics (double wedge scanner and aircraft window) with the angle of incidence $\theta_{\mathrm{i}}$.

The system gain as a function of the backscattered signal frequency $k_{\mathrm{h}}(\Delta f)$ was estimated based on the power spectra of the range gates acquired after ground return. These range gates contain only instrumental noise and no atmospheric signal. If the noise that affects the system is constant with the frequency (white noise), the normalized power spectrum of the acquired noise is identical to the frequency response of the system (Fig. 6). 


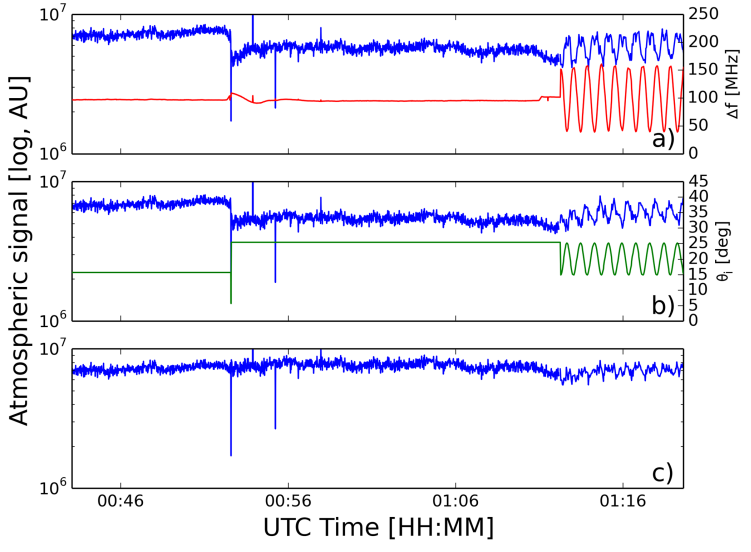

Figure 5. Atmospheric signal (blue) from 26 June averaged between 3 and $4 \mathrm{~km}$ after correcting for acquisition board gain (a), for system gain as a function of the beat signal frequency (b) and additionally for the system gain as a function of the angle of incidence of the laser beam (c). Beat signal frequency (a, red). Angle of incidence of the laser beam (b, green).

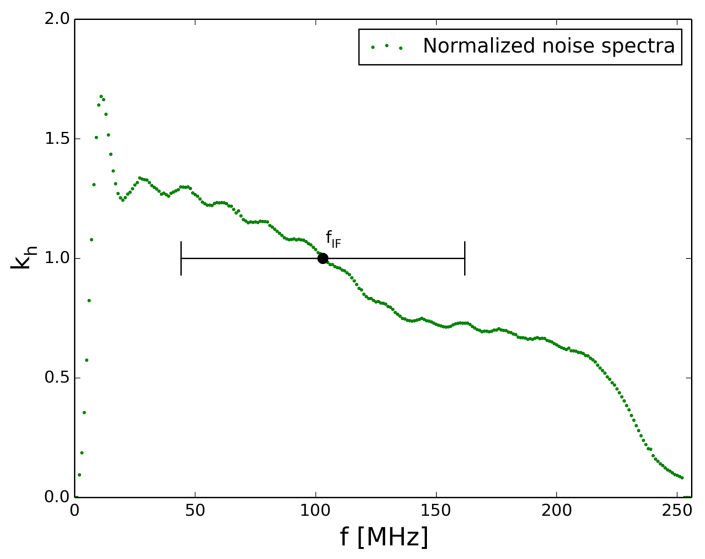

Figure 6. Estimated system frequency response $k_{\mathrm{h}}$ based on the digitized noise spectra. The black dot indicates the beat signal frequency $\left(f_{\mathrm{IF}}=102 \mathrm{MHz}\right)$ when the relative speed between the lidar and the measured range gate is zero. The horizontal line indicates the range of variation of the beat signal frequency produced by the projection of the aircraft speed on the lidar LOS, when the system operates in scanning mode.

This correction is applied to the power spectra of each range gate given by Eq. (6) before computing the power of the backscattered signal. An example of the atmospheric backscattered signal after being corrected by the system gain $k_{\mathrm{h}}$ can be seen in Fig. $5 \mathrm{~b}$.

The transmission of the transceiver optics as a function of the angle of incidence $k_{\theta}(\boldsymbol{I})$ can be estimated based on measurements for which all the other atmospheric and instrumental parameters can be considered to be constant. For a range $R_{\mathrm{k}}$ at which the atmosphere can be considered homogenous, a set of measurements with different angles of

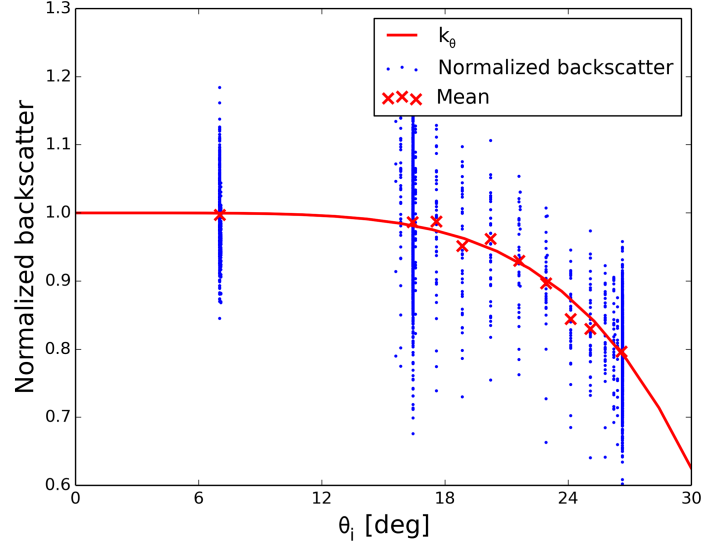

Figure 7. Estimated system response $k_{\theta}$ (red line) as a function of the angle of incidence $\theta_{\mathrm{i}}$ of the laser beam on the aircraft window. The normalized backscatter data points (blue dots) are the averaged measured backscatter power at altitudes between 2 and $3 \mathrm{~km}$ for several vertical profiles and different angles of incidence during the flight on 26 June. The mean values for the normalized backscatter (red crosses) are derived from measurements with similar angle of incidence.

incidence $\left(5,15\right.$ and $25^{\circ}$ off nadir and scanning mode) was used to estimate $k_{\theta}(\boldsymbol{I})$ (Fig. 7). The measurements at 5, 15 and $25^{\circ}$ used for this estimation were pointing perpendicular to the aircraft flying direction to minimize the effects of the system gain changes with the backscattered signal frequency (described above).

$\frac{\left\langle P\left(R_{\mathrm{k}}\right)\right\rangle R_{\mathrm{k}}^{2}}{E_{\mathrm{T}} \eta_{\mathrm{h}} k_{\mathrm{G}} k_{\mathrm{h}}\left(R_{\mathrm{k}}, \boldsymbol{I}\right)}=k_{\theta}\left(\theta_{\mathrm{i}}(\boldsymbol{I})\right) k_{d} k_{\delta}\left(R_{\mathrm{k}}\right) \beta\left(R_{\mathrm{k}}\right) T^{2}\left(R_{\mathrm{k}}\right)$

Several functions were tested to model the relation between the line of sight angle of incidence $\theta_{\mathrm{i}}$ and the received backscattered power. The best agreement was achieved using the following polynomial function (Fig. 7):

$k_{\theta}\left(\theta_{\mathrm{i}}(\boldsymbol{I})\right)=-12 \theta_{\mathrm{i}}^{5}+1$.

Dividing Eq. (15) by Eq. (16) results in

$\left\langle P_{\mathrm{c}}(R)\right\rangle=\frac{\langle P(R)\rangle R^{2}}{E_{\mathrm{T}} \eta_{\mathrm{h}} k_{\mathrm{G}} k_{\mathrm{h}}(R, \boldsymbol{I}) k_{\theta}(\boldsymbol{I})}=k_{d} k_{\delta}(R) \beta(R) T^{2}(R)$,

where $\left\langle P_{\mathrm{c}}(R)\right\rangle$ represents the backscattered power after being corrected for the previously mentioned instrumental effects (Fig. 5c). It can be seen that the instrumental influence on the atmospheric backscatter signal is strongly removed by comparing Fig. 5a and c.

\subsection{Limitations of the instrumental corrections}

As specified in Table 1, the system emits circular polarization and detects the co-polarized component of the backscattered signal, which is attenuated by atmospheric depolarization. There are other factors that have to be taken into ac- 
Table 2. List of flights below CALIPSO (12 June 2013) and over POLIS lidar (other dates). The overflights were defined as the time periods during which the DLR Falcon was flying in the region defined by a square cantered at the POLIS position with sides of $3 \mathrm{~km}$. Dates and time are in UTC.

\begin{tabular}{|c|c|c|c|c|}
\hline Date & DWL time period & Altitude $[\mathrm{m}]$ & DWL mode & $\begin{array}{l}\text { CALIPSO and POLIS } \\
\text { time period }\end{array}$ \\
\hline & Start Stop & & & Start Stop \\
\hline 12 Jun 2013 & $14: 52: 00-14: 56: 00$ & 9418 & Nadir pointing & $14: 52: 00-14: 56: 00$ \\
\hline 26 Jun 2013 & $23: 56: 18-23: 56: 37$ & 7773 & Nadir pointing & $23: 54: 58-23: 57: 02$ \\
\hline 27 Jun 2013 & $00: 20: 34-00: 20: 54$ & 7773 & $5^{\circ}$ off-nadir & 00:20:08-00:22:19 \\
\hline 27 Jun 2013 & $00: 46: 38-00: 46: 57$ & 7773 & $15^{\circ}$ off-nadir & $00: 45: 17-00: 47: 22$ \\
\hline 27 Jun 2013 & 01:00:07-01:00:26 & 7776 & $25^{\circ}$ off-nadir & 00:59:41-01:01:50 \\
\hline 27 Jun 2013 & $01: 23: 37-01: 23: 56$ & 7777 & Scan & $01: 22: 16-01: 24: 21$ \\
\hline 27 Jun 2013 & $01: 55: 31-01: 55: 50$ & 7778 & Nadir pointing & $01: 54: 48-01: 57: 41$ \\
\hline 10 Jul 2013 & $15: 27: 30-15: 27: 47$ & 8743 & Nadir pointing & $15: 00: 00-15: 26: 00$ \\
\hline 11 Jul 2013 & $13: 16: 34-13: 16: 52$ & 8726 & Nadir pointing & 13:08:00-13:29:00 \\
\hline
\end{tabular}

count in the optical path of the LIDAR that cannot be neglected in the calculation of $k_{\delta}(R)$ : the lidar optics, the scanning wedges and the aircraft window. These optical elements can further decrease the signal due to polarization-dependent attenuation. Due to the difficulty to characterize these attenuations, another approximation was used to get a calibrated backscatter and extinction coefficient (Sect. 3.3).

As stated in the Sect. 3.1, the proposed method supposes that the atmospheric extinction corresponding to range gates at distances shorter than $500 \mathrm{~m}$ from the DWL is negligible. Otherwise, the extinction correction will be wrongly estimated. At the moment, this condition limits the application of the presented method to airborne measurements for which the aerosol load of this range gates can be considered negligible. The use of this algorithm for ground-based DWLs would require a previous estimation of the extinction corresponding to this range gates based on other sources.

\subsection{Calibration of the DWL signal}

Based on the measurements of a ground-based aerosol lidar, an atmospheric model with distinct aerosol layers is derived (Fig. 8). Each layer $L_{\mathrm{n}}$ of the atmospheric model represents an aerosol type and is defined as a region in which the particle depolarization ratio, the lidar ratio and the wavelength dependency of the extinction coefficient are considered to be constant.

Because the ground-based measurements of the backscatter coefficient $\beta_{532}^{\text {POLIS }}(R)$ and extinction coefficient $\alpha_{532}^{\text {POLIS }}(R)$ are performed at $532 \mathrm{~nm}$ by the aerosol lidar POLIS (Sect. 4.2), we have to rewrite Eq. (17) in terms of the atmospheric parameters at this wavelength in order to use ground-based measurements to calculate the DWL calibration constant corresponding to each aerosol type. For a given aerosol type and size distribution, it is possible to estimate the backscatter and extinction coefficient at $2 \mu \mathrm{m}$

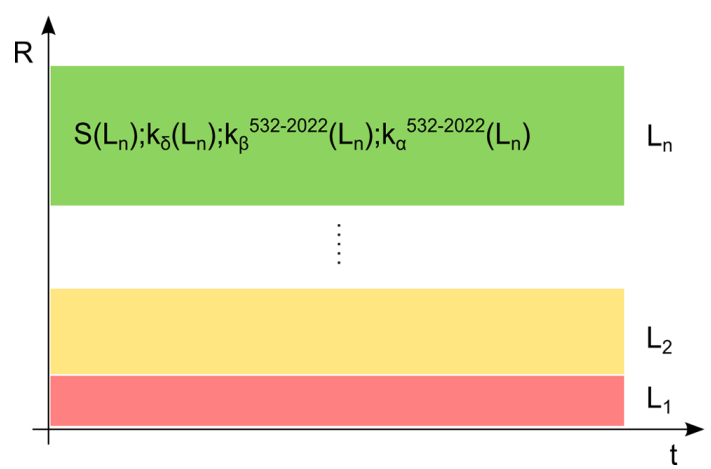

Figure 8. Scheme of the atmospheric layers with different aerosol types $\left(L_{\mathrm{n}}\right)$, where $S_{532}\left(L_{\mathrm{n}}\right)$ is the lidar ratio, $k_{\beta}^{532 \rightarrow 2022}\left(L_{\mathrm{n}}\right)$ and $k_{\alpha}^{532 \rightarrow 2022}\left(L_{\mathrm{n}}\right)$ are the conversion factor of the backscatter and extinction coefficient, respectively, and $k_{\delta}\left(L_{\mathrm{n}}\right)$ the system depolarization response corresponding to the aerosol type. Within each layer, the aerosol properties are assumed to be constant.

by applying a wavelength conversion factor $\left(k_{\beta}^{532 \rightarrow 2022}\right.$ and $k_{\alpha}^{532 \rightarrow 2022}$ ).

Rewriting Eq. (17) in terms of $\beta_{532}^{\mathrm{POLIS}}(R)$ and $\alpha_{532}^{\mathrm{POLIS}}(R)$ yields

$$
\begin{aligned}
& \left\langle P_{\mathrm{c}, 2 \mu \mathrm{m}}(R)\right\rangle=k_{d} k_{\delta}\left(L_{\mathrm{n}}\right) \beta_{532}^{\mathrm{POLIS}}(R) k_{\beta}^{532 \rightarrow 2022}\left(L_{\mathrm{n}}\right) \\
& \exp \left[-2 \int_{0}^{R} \alpha_{532}^{\mathrm{POLIS}}(r) k_{\alpha}^{532 \rightarrow 2022}\left(L_{\mathrm{n}}\right) \mathrm{d} r\right]
\end{aligned}
$$

All parameters that remain constant for a given layer can be grouped in a single constant $k\left(L_{\mathrm{n}}\right)$, resulting in the following equation:

$\left\langle P_{\mathrm{c}, 2 \mu \mathrm{m}}(R)\right\rangle=k\left(L_{\mathrm{n}}\right) \beta_{532}^{\mathrm{POLIS}}(R) T_{2 \mu \mathrm{m}}^{2}(R)$, 
with $\quad T_{2 \mu \mathrm{m}}^{2}(R)=\exp \left[-2 \int_{0}^{R} \alpha_{532}^{\mathrm{POLIS}}(r) k_{\alpha}^{532 \rightarrow 2022}\left(L_{\mathrm{n}}\right) \mathrm{d} r\right]$ and

$k\left(L_{\mathrm{n}}\right)=k_{d} k_{\delta}\left(L_{\mathrm{n}}\right) k_{\beta}^{532 \rightarrow 2022}\left(L_{\mathrm{n}}\right)$.

In order to get a linear relation between the measured and corrected backscattered power $\left\langle P_{\mathrm{c}, 2 \mu \mathrm{m}}(R)\right\rangle$ and the backscatter coefficient $\beta_{532}^{\text {POLIS }}(R)$ measured by the groundbased lidar, it is necessary to remove the effect of the atmospheric attenuation $T_{2 \mu \mathrm{m}}^{2}$. The atmospheric attenuation at $2 \mu \mathrm{m}$ can be estimated based on the extinction coefficient measured by the ground-based lidar $\alpha_{532}^{\text {POLIS }}(R)$ and its corresponding conversion factor $k_{\alpha}^{532 \rightarrow 2022}\left(L_{\mathrm{n}}\right)$.

In general, if the aerosol size distribution follows the Junge power law or the wavelength difference is small, the conversion factor $k_{\alpha}^{532 \rightarrow 2022}$ can be calculated using the Ångström exponent, which can be obtained from literature references (e.g., Ansmann and Müller, 2005). However, in our case the mentioned requirements are not fulfilled. For this reason, measurements from a collocated sun photometer were used to estimate this dependency (Sect. 4.3).

Finally, the conversion constant $k\left(L_{\mathrm{n}}\right)$ corresponding to each layer can be estimated applying a LSF (least squares fit) between the backscatter coefficient $\beta_{532}^{\text {POLIS }}$ measured by the ground-based lidar POLIS and the extinction-corrected signal measured by the DWL from

$\frac{\left\langle P_{\mathrm{c}, 2 \mu \mathrm{m}}(R)\right\rangle}{T_{2 \mu \mathrm{m}}^{2}(R)}=k\left(L_{\mathrm{n}}\right) \beta_{532}^{\text {POLIS }}(R)$.

The principle of the calibration is shown in Fig. 9 (blue box).

\subsection{Backscatter and extinction coefficient retrieval}

Based on the layer distribution and the conversion coefficients $k\left(L_{\mathrm{n}}\right)$ calculated for each layer, it is possible to retrieve the backscatter coefficient at $532 \mathrm{~nm}$ based on the $2 \mu \mathrm{m}$ measurements $\beta_{532}^{\mathrm{DWL}}$ through an iterative process (Fig. 9, purple box).

For the first step it is assumed that $\alpha_{532}^{\mathrm{DWL}}(R)=0$. This leads to $T_{2 \mu \mathrm{m}}^{2}(R)=1$. Based on this approximation, it is possible to calculate a first order approximation of the backscatter $\beta_{532}^{\mathrm{DWL}}(R)$ for each layer of the model using Eq. (22) and the corresponding constant $k\left(L_{\mathrm{n}}\right)$

$$
\left\langle P_{\mathrm{c}, 2 \mu \mathrm{m}}(R)\right\rangle k^{-1}\left(L_{\mathrm{n}}\right)=\beta_{532}^{\mathrm{DWL}}(R)
$$

Then, using the estimated backscatter coefficient $\beta_{532}^{\mathrm{DWL}}(R)$ and the lidar ratio $S_{532}^{\text {POLIS }}\left(L_{\mathrm{n}}\right)$ provided by the ground-based lidar, a new value for the extinction coefficient $\alpha_{532}^{\mathrm{DWL}}(R)$ can be estimated:

$\alpha_{532}^{\mathrm{DWL}}(R)=\beta_{532}^{\mathrm{DWL}}(R) S_{532}^{\mathrm{POLIS}}\left(L_{\mathrm{n}}\right)$.

Based on the extinction coefficient $\alpha_{532}^{\mathrm{DWL}}(R)$ and its conversion factor $k_{\alpha}^{532 \rightarrow 2022}\left(L_{\mathrm{n}}\right)$, the new transmission $T_{2 \mu \mathrm{m}}^{2}(R)$ is calculated:

$T_{2 \mu \mathrm{m}}^{2}(R)=\exp \left[-2 \int_{0}^{R} \alpha_{532}^{\mathrm{DWL}}(r) k_{\alpha}^{532 \rightarrow 2022}\left(L_{\mathrm{n}}\right) \mathrm{d} r\right]$.

Finally, the calculated transmission is used to retrieve a new approximation for the backscatter coefficient:

$\frac{\left\langle P_{\mathrm{c}, 2 \mu m}(R)\right\rangle}{T_{2 \mu \mathrm{m}}^{2}(R)} k^{-1}\left(L_{\mathrm{n}}\right)=\beta_{532}^{\mathrm{DWL}}(R)$.

The procedure can be written in form of an iterative equation (Fig. 9, grey box inside purple box):

$\beta_{532, i}^{\mathrm{DWL}}(R)=\frac{\left\langle P_{\mathrm{c}, 2 \mu \mathrm{m}}(R)\right\rangle}{T_{2 \mu \mathrm{m}, i-1}^{2}(R)} \frac{1}{k\left(L_{\mathrm{n}}\right),}$

$\alpha_{532, i}^{\mathrm{DWL}}(R)=\beta_{532, i}^{\mathrm{DWL}}(R) S_{532}^{\mathrm{POLIS}}\left(L_{\mathrm{n}}\right)$,

with the iteration number $i$ and $T_{2 \mu \mathrm{m}, 0}^{2}(R)=1$ as starting value.

\section{Description of the data sets}

\section{1 $2 \mu \mathrm{m}$ DWL data set}

During SALTRACE, the DLR Falcon research aircraft performed 31 research flights. The $2 \mu \mathrm{m}$ DWL was operational during all flights, totalizing $75 \mathrm{~h}$ of measurements. For this work, we will focus on the research flights conducted in the Barbados region where the Falcon overflew the groundbased lidar POLIS (see Table 2) and on an overpass of the CALIPSO lidar satellite in the Dakar region during the flight on 12 June 2013.

During the flight on 26 June, planned as calibration flight, eight overflights (Fig. 10) were conducted with the system operating in different modes and altitudes with relatively constant atmospheric conditions. It is for this reason that the correction of the different instrumental effects (Sect. 3.1) and the calibration constants (Sect. 3.3) where calculated based on the measurements obtained from this flight.

Because the calibration method proposed in the previous section supposes that the extinction is 0 for range gates at distances shorter than $500 \mathrm{~m}$, only the overflights performed above the aerosol layers were used for the calculation of the calibration constants. For these cases, the SAL top was at around $4000 \mathrm{~m}$.

In order to validate the method and verify the stability of the instrumental corrections and derived calibrations constants, the constants were applied to the measurements of other three flights and compared, during the overflights, with the profiles measured by the POLIS ground-based lidar and CALIPSO satellite. For this propose the flights on 12 June and 10 and 11 July were used. 


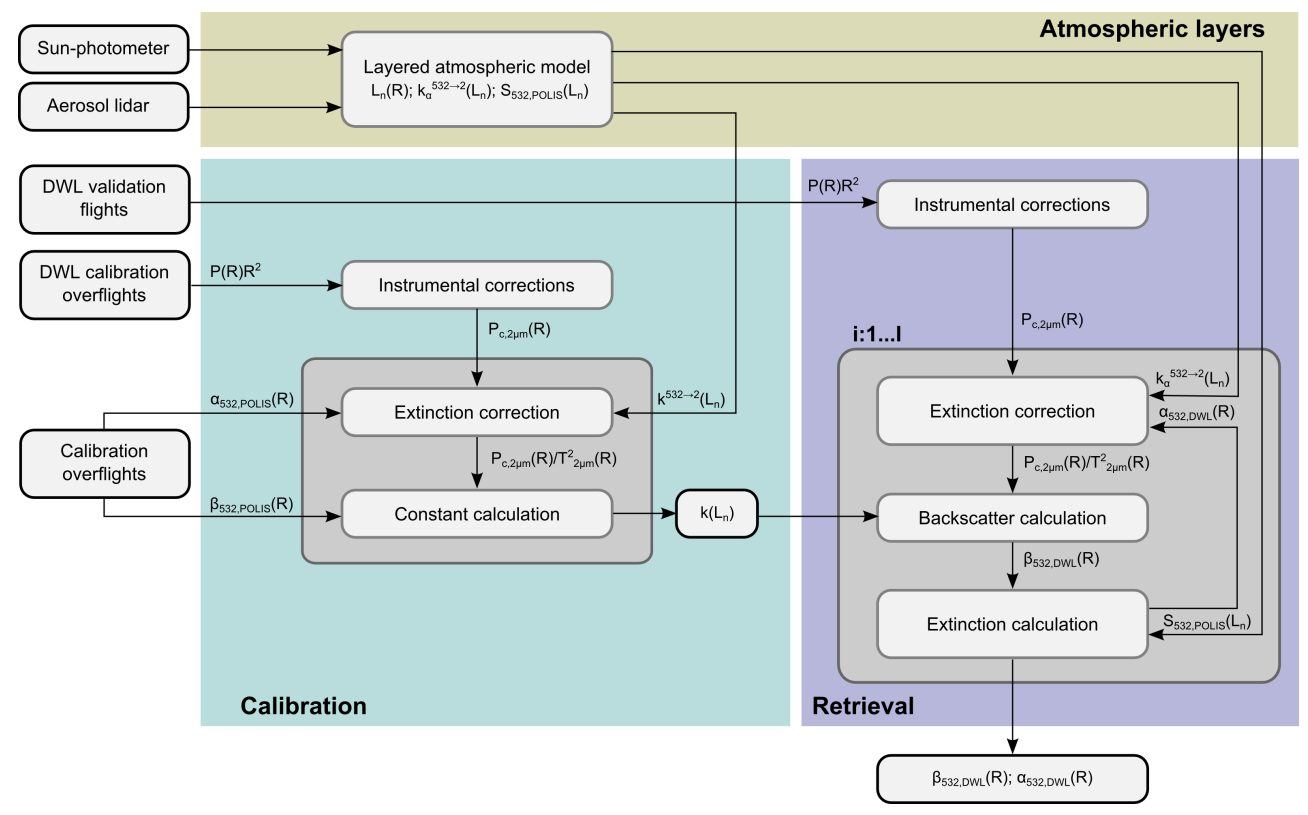

Figure 9. Overview of the calibration and retrieval procedure.

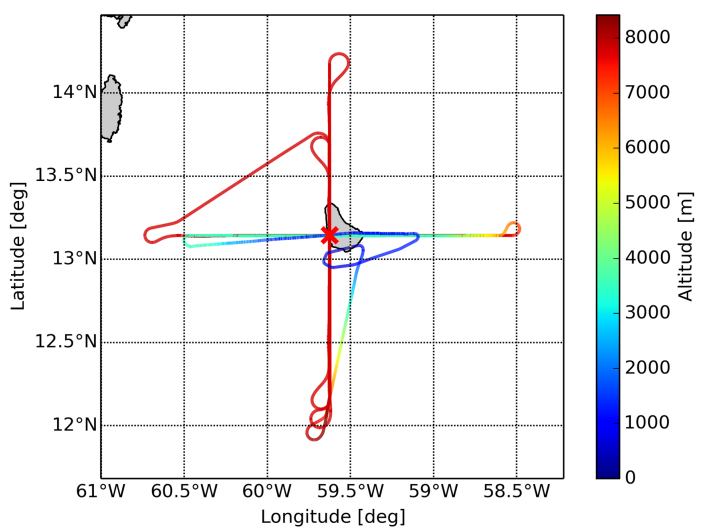

Figure 10. Track for the calibration flight on 26 June. The red cross indicates the position of the ground-based lidar POLIS.

\subsection{Ground-based lidar POLIS data set}

POLIS is a small portable six-channel lidar system measuring the $\mathrm{N}_{2}$-Raman shifted backscatter at 387 and $607 \mathrm{~nm}$ (nighttime measurements) and the elastic backscatter (cross and parallel polarized) at 355 and $532 \mathrm{~nm}$ (day- and nighttime measurements). The full overlap of POLIS was about 200 to $250 \mathrm{~m}$ depending on system settings. The system was developed by the Meteorological Institute of the LudwigMaximilians-Universität München (Freudenthaler et al., 2009, 2015) and was extended to the six channels mentioned above in the meantime. The measurements site was located in the southwestern part of Barbados at the Caribbean Institute for Meteorology and Hydrology (CIMH) $\left(13^{\circ} 08^{\prime} 55^{\prime \prime} \mathrm{N}, 59^{\circ}\right.$ $37^{\prime} 30^{\prime \prime} \mathrm{W}, 110 \mathrm{~m}$ a.s.l.). For nighttime the Raman methodol- ogy (Ansmann et al., 1992) was applied to derive independent profiles of the particle extinction coefficient $\alpha_{532}^{\mathrm{POLIS}}(R)$, the particle backscatter coefficient $\beta_{532}^{\text {POLIS }}(R)$ and thus of the extinction-to-backscatter ratio $S_{532}^{\text {POLIS }}(R)$ (lidar ratio). A possible wavelength dependence between the Raman-shifted wavelengths and the elastically backscattered wavelengths is considered in this methodology, but as both the Saharan dust aerosols as well as marine aerosols are large compared to the lidar wavelength, the wavelength dependency can be neglected in this study. As the signal-to-noise ratio of the Raman signals is comparably low, temporal averages of 1 to 2 hours were used, taking care of the temporal stability of the atmospheric layering. The lidar ratio was then used to analyze the elastic backscattered signals (from both day- and nighttime measurements) with the Klett-Fernald (Fernald, 1984) inversion algorithm to achieve better temporal and vertical resolution.

\subsection{AERONET sun photometer data set}

A CIMEL sun photometer from the AERONET network was operating in Barbados during SALTRACE, performing AOD (aerosol optical depth) measurements at eight different wavelengths. The system was deployed in the facilities of the CIMH collocated with the aerosol lidar POLIS. The site name in the AERONET database is "Barbados_SALTRACE".

The calibration algorithm presented in the previous section requires the extinction coefficient conversion factor $k_{\alpha}^{532 \rightarrow 2022}$ corresponding to each aerosol type as input. In this particular case, where the POLIS lidar operates at $532 \mathrm{~nm}$ and the DWL operates at $2.022 \mu \mathrm{m}$, the relation between the 
extinction coefficients at these two wavelengths, for each aerosol type, has to be determined.

The wavelength dependency of the AOD is characterized by the Ångström exponent, which is usually defined as the slope on the logarithm of the AOD vs. the logarithm of the wavelength. Nevertheless, for this case, the conventional linear fit performed to estimate the Ångström exponent will not provide a good approximation (Fig. 11). For this reason, a second-order fit (King and Byrne, 1976; Eck, et al. 1999) was used to model the logarithm of the AOD as a function of the logarithm of the wavelength. Based on the estimated function, the extinction coefficient conversion factor from $532 \mathrm{~nm}$ to $2 \mu \mathrm{m} k_{\alpha}^{532 \rightarrow 2022}$ was calculated.

The sun-photometer-measured AOD is equal to the column-integrated atmospheric extinction coefficient. If different aerosol types are present, the AOD wavelength dependency will depend on the wavelength dependency of the extinction coefficient of each aerosol type and the relative contribution of each one to the total AOD. In order to determine the wavelength dependency of the extinction coefficient corresponding to the different aerosol types identified by the POLIS lidar, a specific set of sun photometer measurements was used.

The marine aerosol extinction coefficient behavior as a function of the wavelength can be estimated by analyzing the AOD as a function of the wavelength for those measurement periods during which no dust or other aerosol types were present. An example of this situation occurred on 7 July. As can be seen in the Fig. 11c, the fitted function has a positive curvature, which is compatible with an aerosol size distribution dominated by intermediate-sized coarse mode particles (O'Neill et al., 2008) as expected for the marine boundary layer.

For the case of the aerosol mixture layer, a different approach was applied. Because there is no day during which only a layer of aerosol mixture was present, only a coarse estimation of the AOD as a function of the wavelength can be achieved. During 6 July, only two aerosol layers were present, the lower one corresponding to marine aerosol and the upper one corresponding to a mixture of aerosols. The contribution of the marine aerosol to the measured total AOD is lower than the contribution of the mixed layer. Based on this fact, the wavelength dependency of the measured AOD can be considered, taking into account the limitations, as representative of the mixed aerosol type extinction coefficient wavelength behavior. Due to its mixed nature, the spectral dependency of this layer is expected to be intermediate with respect to the marine layer and the Saharan layer. The fitted function (Fig. 11b) shows a positive but lower curvature, which is coincident with the expected behavior.

For the case of the Saharan dust present on the uppermost aerosol layer during the flights on 26 June and 10 and 11 July 2013, a similar approach to the one used for the case of the aerosol mixture was applied. Nevertheless, because the contribution of the dust layer to the total AOD is

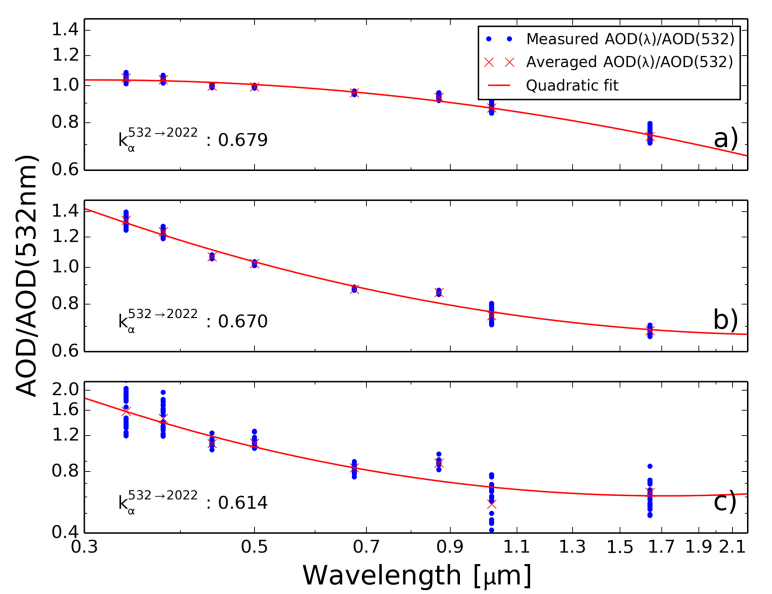

Figure 11. Estimated extinction coefficient conversion factor $k_{\alpha}^{532 \rightarrow 2022}$ based on sun photometer AOD measurements for three different aerosol types. (a) Dust: the wavelength dependency was calculated based on 103 AOD measurements (blue dots) on 26 June (between 12:07 and 21:05 UTC), 10 July (between 10:33 and 21:20 UTC) and 11 July (between 13:16 and 20:09 UTC). (b) Mixed aerosol: for this case, 33 AOD measurements taken on the 6 July, between 15:48 and 21:26 UTC, were used for the estimation. (c) Marine aerosol: 31 AOD measurements from 7 July, between 12:30 and 19:58 UTC, were used.

much larger than the contribution of the other two layers, the approximation is much more accurate than in the previous case. In this case, the fitted function shows a negative curvature, which is consistent with the results obtained during SAMUM-2 (Toledano et al., 2011).

The calculated conversion factors for each aerosol type are presented in Table 3.

\section{Results and discussion}

\subsection{Calibration}

As stated in Sect. 3.3, the calculation of the calibration constants $k\left(L_{\mathrm{n}}\right)$ starts with the classification of different aerosol layers based on the POLIS measurements taken for each DLR Falcon overflight on 26 June 2013 (Fig. 12). This classification is based on measurements of the lidar intensive properties, the lidar ratio and the particle linear depolarization ratio. The classification scheme is described by Groß et al. (2013). The layer altitudes and properties derived from the overflights were supposed to remain constant for the rest of the flight.

Then, using the extinction coefficient measured by POLIS during each overflight and the extinction coefficient conversion factor calculated from the sun photometer measurements, the backscattered power profiles measured by the DWL during the overflights were corrected by extinction as stated in the Eq. (21). The backscattered DWL profiles cor- 

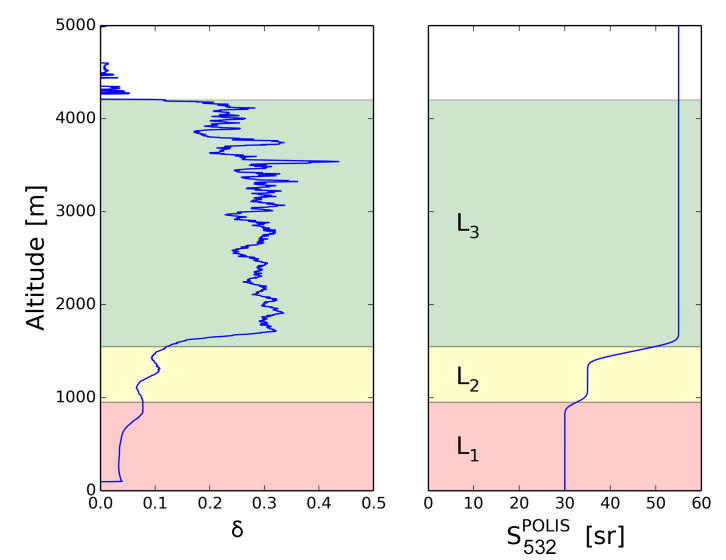

Figure 12. Measured particle linear depolarization ratio $\delta$ and the derived lidar ratio $S_{532}^{\text {POLIS }}$ for the first calibration overflight (23:56:18-23:56:37 UTC) on 26 June obtained by the ground-based lidar POLIS and the aerosol layers with boundary layer $L_{1}$ (red, 0 to $1000 \mathrm{~m}$ ), mixed layer $L_{2}$ (yellow, 1000 to $1500 \mathrm{~m}$ ) and SAL $L_{3}$ (green, 1500 to $4200 \mathrm{~m}$ ).

responding to each overflight result from the average of the vertical profiles acquired during the time periods defined in Table 2. Each averaged measured profile is filtered using a fixed manually adjusted threshold $\left(\beta_{532}^{\mathrm{DWL}}<10 \mathrm{Mm}^{-1} \mathrm{sr}^{-1}\right)$ in order to remove clouds.

Finally, the calibration constants $k\left(L_{\mathrm{n}}\right)$ corresponding to each layer were estimated using the backscatter coefficient measured by POLIS for the six overflights by a linear LSF (Fig. 13). The estimated inverse of the constants $k^{-1}\left(L_{\mathrm{n}}\right)$ and its standard deviation $\sigma_{k^{-1}\left(L_{\mathrm{n}}\right)}$ obtained from the LSF are resumed in Table 3.

The data in Fig. 13 show a higher spread in the measurements corresponding to the boundary layer $\left(L_{1}\right)$, which is explained by the higher horizontal inhomogeneity of that layer and the accumulated error in the retrieval of the upper layers. In contrast, the measurements corresponding to the mixed layer $\left(L_{2}\right)$ and SAL $\left(L_{3}\right)$ show a lower spread compatible with their higher homogeneity.

Although the calculated calibration constants $k$ for each aerosol type are very similar, this result seems to be just casual. Each calibration constant (Eq. 20) includes depolarization effects $k_{\delta}$ and the wavelength dependency of the backscatter coefficient $k_{\beta}^{532 \rightarrow 2022}$ which are strongly dependent of the aerosol type. The retrieval of extinction-corrected backscatter coefficients profiles still requires the definition of aerosol layers with different lidar ratios to perform the extinction correction. For these reasons, and even though the retrieved calibration constants are similar in this case, the use of different layers is still required.

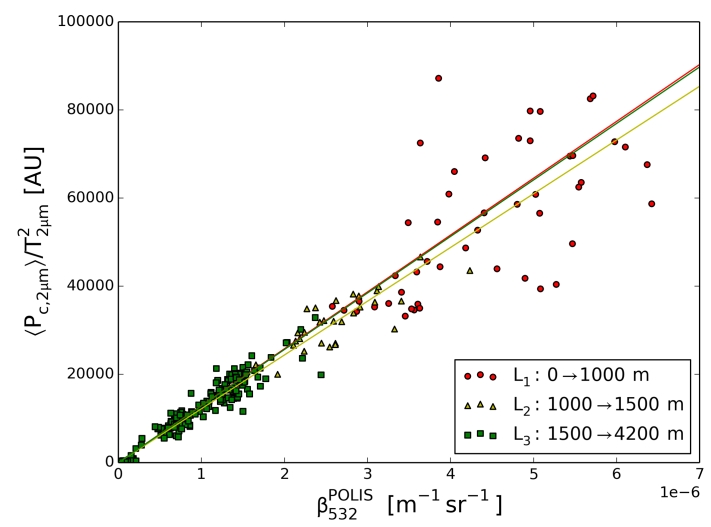

Figure 13. Correlation between the extinction-corrected backscattered power of the DWL and the POLIS measured backscatter coefficient for the six calibration overflights on the 26 June and the three different aerosol layers: boundary layer (red dots), mixed layer (yellow triangles) and SAL (green squares).

\subsection{Backscatter and extinction coefficient retrieval for the flight on 26 June}

Using the constants calculated in the previous step and applying the iterative Eqs. (26) and (27) for each measured vertical profile, the backscatter and extinction coefficients for the whole flight were calculated (Fig. 14). The calculation was conducted using five iterations for each profile. The retrieved vertical profiles of the backscatter coefficient from the DWL and POLIS corresponding to the overflights are shown for comparison in Fig. 15.

As can be seen in Figs. 13 and 14, the SAL upper and lower boundaries have a constant altitude of 1.5 and $4 \mathrm{~km}$, respectively, for the whole flight, which corresponds to a square area with sides of $200 \mathrm{~km}$ and centered in Barbados. It can also be noted that the SAL has an internal two layer structure with a boundary at around $2.5-3 \mathrm{~km}$. While both sublayers are horizontally homogeneous, the lower sub-layer is characterized by a higher backscatter coefficient $\beta_{532}^{\mathrm{DWL}}$ $\left(\sim 1.5 \mathrm{Mm}^{-1} \mathrm{sr}^{-1}\right)$ than the upper one $\left(\sim 0.7 \mathrm{Mm}^{-1} \mathrm{sr}^{-1}\right)$.

For the measurements corresponding to the time period between 00:05 and 00:20 UTC, a perturbation of the internal structure of the SAL can be observed in coincidence with the presence of clouds on the top of the mixed layer. The vertical wind speed, also available from the DWL, shows a relatively constant upward wind flow with a mean speed of $0.3 \mathrm{~m} \mathrm{~s}^{-1}$ above the cloud layer, which is likely to be associated with convection processes.

The non-averaged DWL retrievals presented in Fig. 15 (black dots) illustrate the higher variability of the boundary layer observed during the calibration constant retrieval. Most of the aerosol load is located in the lower $500 \mathrm{~m}$ of the boundary layer, with backscatter coefficients $\beta_{532}^{\mathrm{DWL}}$ up to $6 \mathrm{Mm}^{-1} \mathrm{sr}^{-1}$. 
Table 3. Extinction coefficient conversion factor $k_{\alpha}^{532 \rightarrow 2022}$, inverse of the calibration constants $k^{-1}$ and its corresponding standard deviation $\sigma_{k^{-1}}$ retrieved for each layer. The mean $\mu\left[\mathrm{Mm} \mathrm{sr}^{-1}\right]$ and the standard deviation $\sigma\left[\mathrm{Mm} \mathrm{sr}^{-1}\right]$ of the difference between the retrieved backscatter coefficient from the DWL and POLIS are also shown together with the relative standard deviation $\left(\sigma / \mu_{\mathrm{POLIS}}\right)$.

\begin{tabular}{lllllll}
\hline Layer & \multicolumn{3}{c}{ Calibration } & \multicolumn{3}{c}{ Error analysis } \\
\hline & $k_{\alpha}^{532 \rightarrow 2022}$ & $k^{-1}$ & $\sigma_{k^{-1}}$ & $\mu$ & $\sigma$ & RSD \\
\hline Boundary layer $\left(L_{1}\right)$ & 0.614 & $7.75 \times 10^{-11}$ & $2.26 \times 10^{-12}$ & -0.185 & 0.572 & 0.162 \\
Mixed layer $\left(L_{2}\right)$ & 0.670 & $8.20 \times 10^{-11}$ & $1.80 \times 10^{-12}$ & 0.126 & 0.352 & 0.111 \\
Saharan Air Layer $\left(L_{3}\right)$ & 0.679 & $7.80 \times 10^{-11}$ & $7.85 \times 10^{-13}$ & -0.068 & 0.217 & 0.165 \\
\hline
\end{tabular}
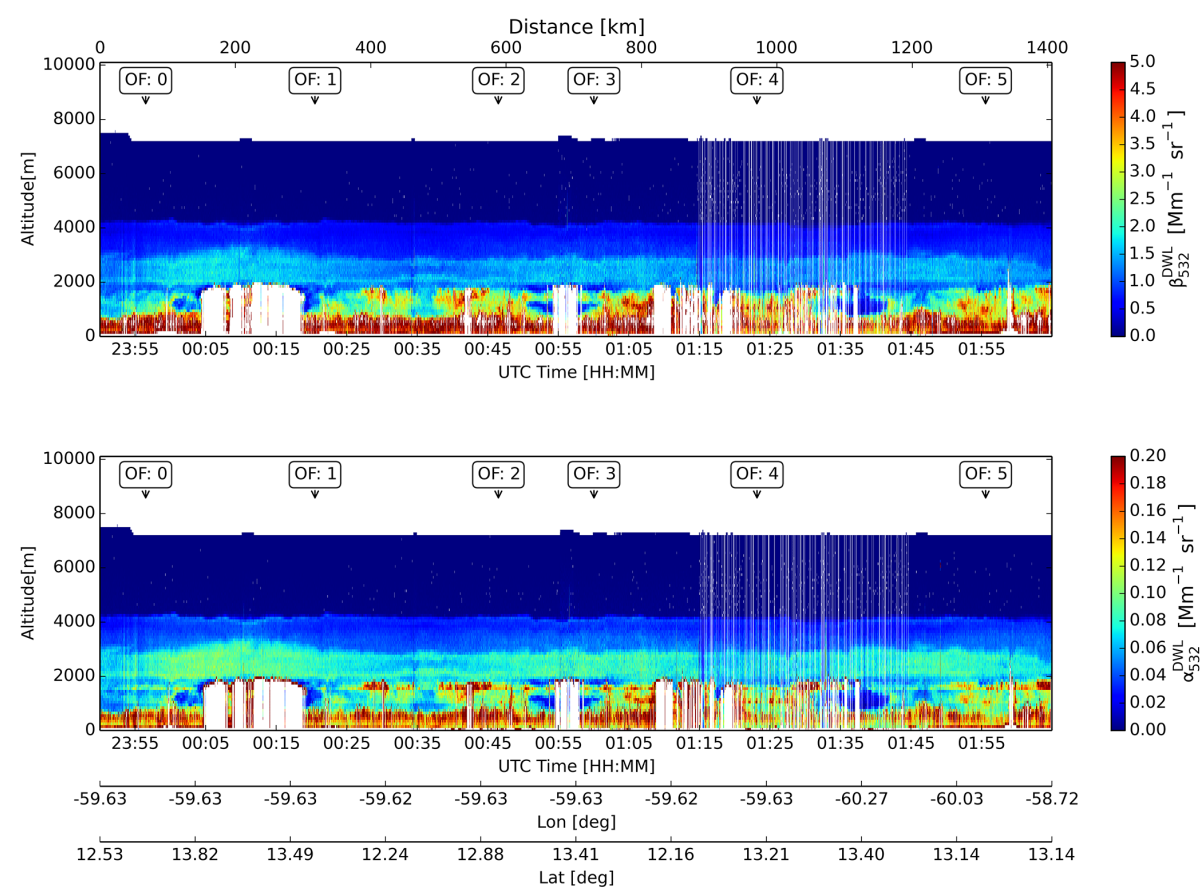

Figure 14. Overview of the retrieved backscatter and extinction coefficient for the flight on 26 June. The label "OF" indicates the time of the overflight over POLIS lidar. The white color indicates regions where no atmospheric signal is available (e.g., below clouds, low laser energy).

\subsection{Validation of the calculated calibration constants}

The calibration constants calculated from the measurements taken on 26 June 2013 and the layer model derived from the POLIS measurements on 10 and 11 July 2013 were used to retrieve the backscatter and extinction coefficient for the flights on 10 and 11 July. In this case, only the backscatter coefficient is shown (Fig. 16). The results were compared to the POLIS lidar measurements during the Falcon overflights (Fig. 17).

Similar to the previous case, the retrieved backscatter coefficient profiles for 10 and 11 July show a constant SAL upper boundary at 5 and $4.5 \mathrm{~km}$, respectively. The SAL exhibit for both days the same two sub-layer structure as found on 26 June, with a higher backscatter coefficient in the lower layer than in the upper one.
The comparisons with the POLIS ground-based lidar show good agreement for the retrieved backscatter coefficient corresponding to the SAL. The overall shapes of the vertical profiles as well as the altitudes of the maximums and minimums correspond to each other.

\subsection{Uncertainty estimation}

For each overflight belonging to the calibration flight and validation flights, the retrieved averaged vertical backscatter coefficient profile calculated for each iteration was compared to the measured POLIS vertical profile (Figs. 14 and 16) in order to analyze the root-mean-square difference as a function of the iteration number (Fig. 18). It can be seen that the algorithm converges after two or three iterations. For this case, five iterations were performed for all other retrievals. 

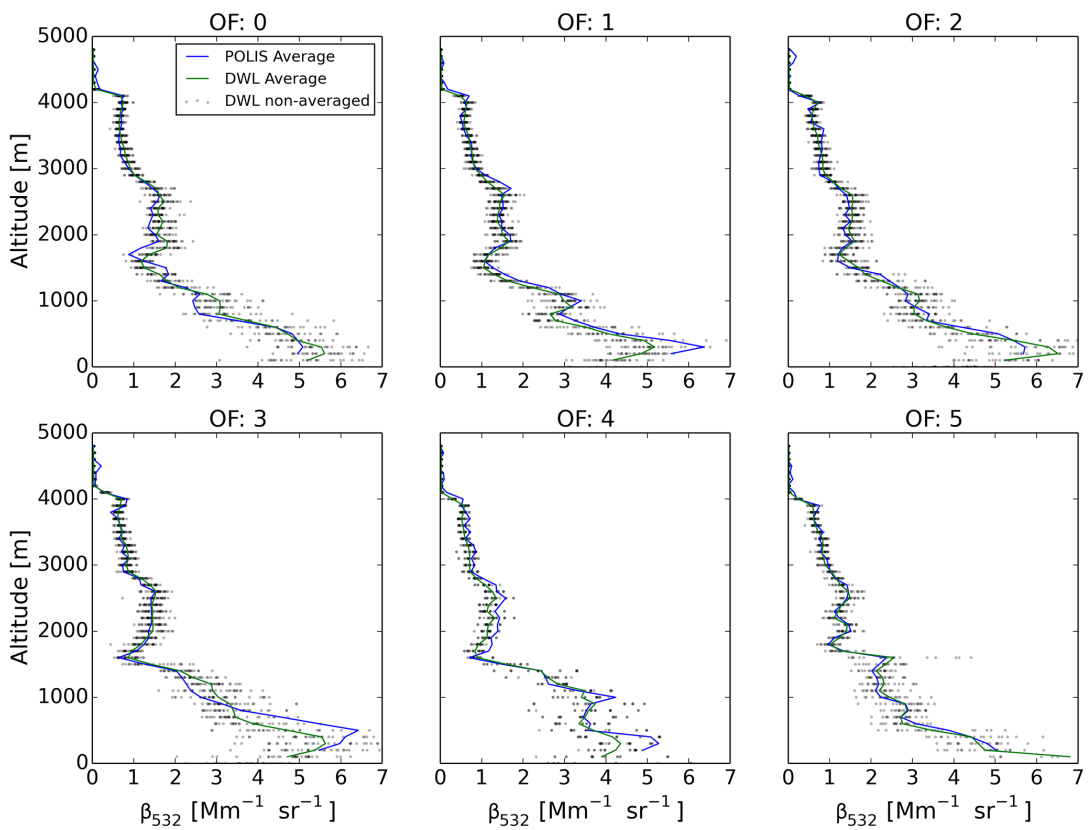

Figure 15. Comparison of the non-averaged (grey dots) and averaged (green) backscatter coefficient profiles corresponding to the retrieved data for the flight on the 26 June and the averaged profiles measured by POLIS (blue) during the Falcon overflights (OF).
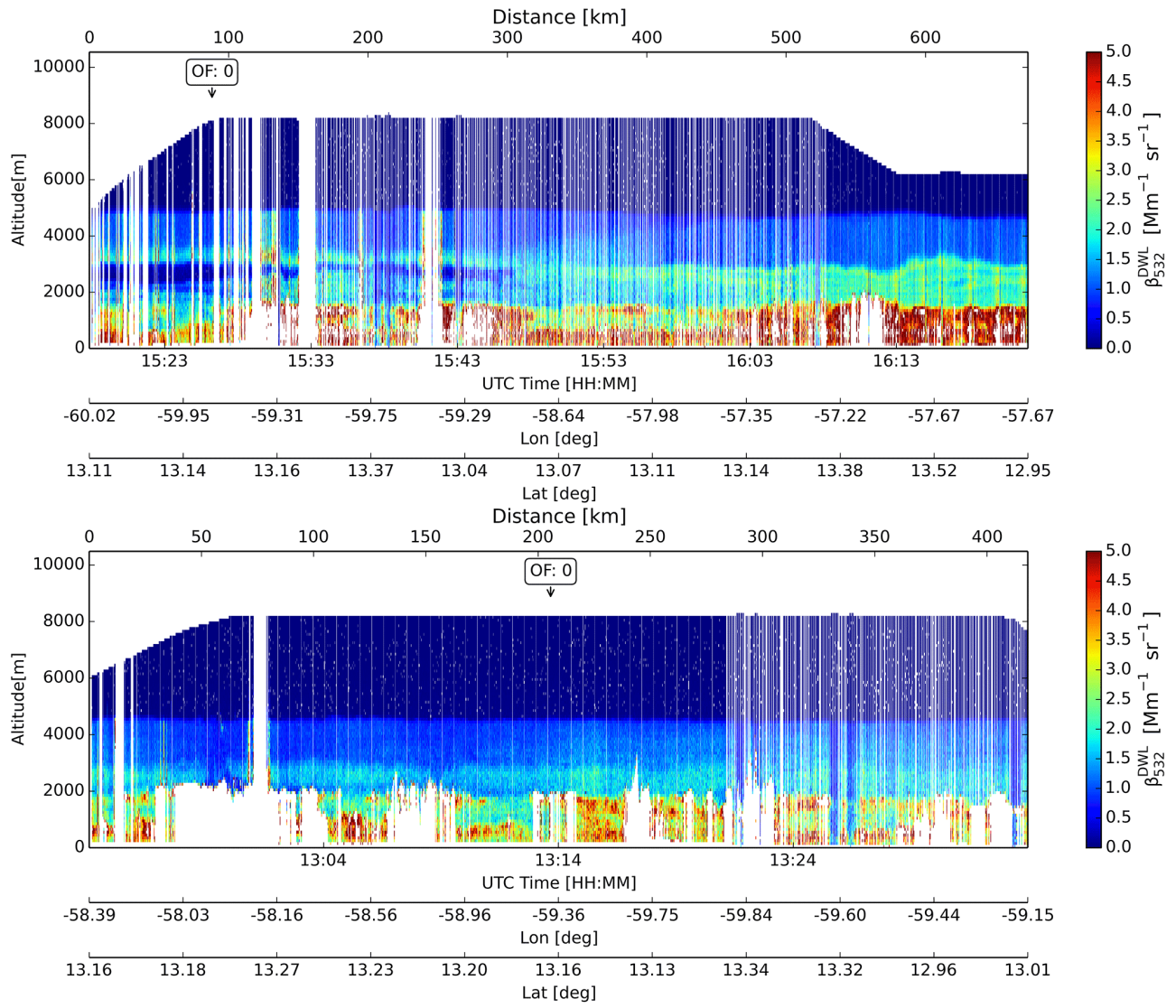

Figure 16. Overview of the retrieved backscatter coefficient for the flights on the 10 July (upper panel) and 11 July (lower panel). The label "OF" indicates the approximated time of the overflight over POLIS lidar. The white color indicates regions were no atmospheric signal is available (e.g., below clouds, low laser energy). 
Table 4. Mean error $\mu\left[\mathrm{Mm} \mathrm{sr}^{-1}\right]$ and standard deviation $\sigma\left[\mathrm{Mm} \mathrm{sr}^{-1}\right]$ as function of the aerosol layer and extinction coefficient conversion factor.

\begin{tabular}{|c|c|c|c|c|c|c|}
\hline \multirow[t]{2}{*}{ Layer } & \multicolumn{2}{|c|}{$k_{\alpha}^{532 \rightarrow 2022}$} & \multicolumn{2}{|c|}{$k_{\alpha}^{532 \rightarrow 2022} 20 \%$ higher } & \multicolumn{2}{|c|}{$k_{\alpha}^{532 \rightarrow 2022} 20 \%$ lower } \\
\hline & $\mu$ & $\sigma$ & $\mu$ & $\sigma$ & $\mu$ & $\sigma$ \\
\hline Boundary layer $\left(L_{1}\right)$ & -0.185 & 0.572 & -0.362 & 0.577 & -0.309 & 0.538 \\
\hline Mixed layer $\left(L_{2}\right)$ & 0.126 & 0.352 & 0.027 & 0.348 & 0.029 & 0.342 \\
\hline Saharan Air layer $\left(L_{3}\right)$ & -0.068 & 0.217 & -0.085 & 0.217 & -0.077 & 0.232 \\
\hline
\end{tabular}
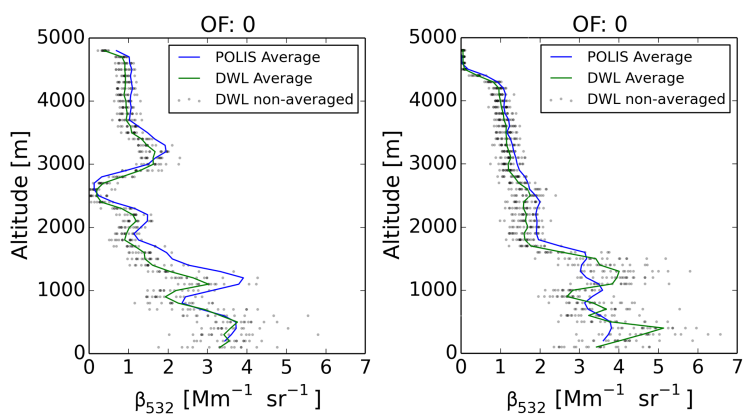

Figure 17. Comparison of the non-averaged (grey dots) and averaged (green) backscatter coefficient profiles corresponding to the retrieved data for the flights on 10 July (left) and 11 July (right), and the averaged profiles measured by POLIS (blue) during the Falcon overflights (OF).

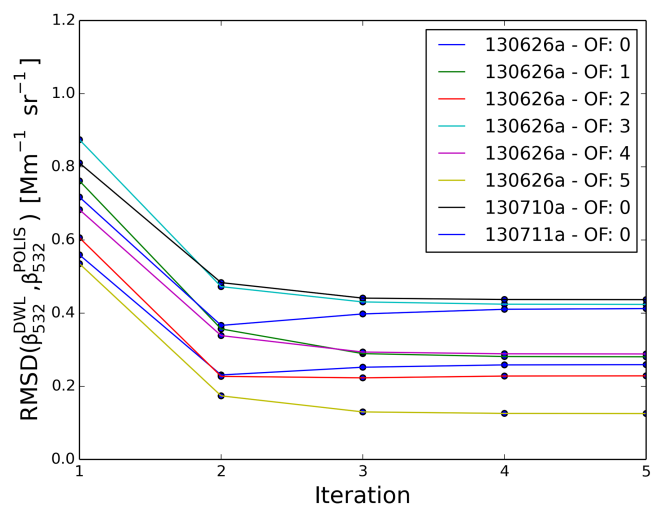

Figure 18. Root-mean-square difference (RMSD) between the backscatter coefficients derived from the DWL and POLIS, calculated for each iteration and overflight. The backscatter coefficients of the three layers are used for the calculation.

In order to characterize the uncertainties of the DWL backscatter coefficient retrieval, the difference between the averaged DWL backscatter profiles and the POLIS measurements is shown as a histogram for each layer (Fig. 19) with their corresponding mean difference and the standard deviation of the differences.

Figure 19 shows a change in the standard deviation as a function of the measured layer. The largest standard deviation is found in the boundary layer. This can be explained
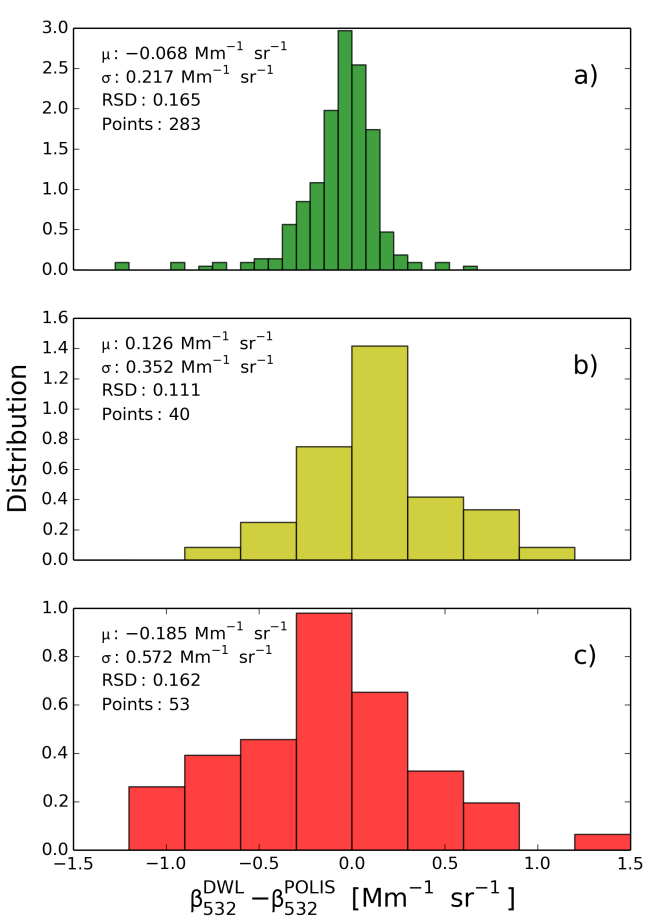

Figure 19. Distribution of the difference between the averaged retrieved DWL backscatter coefficient profiles and the averaged POLIS profiles for each overflight and layer on 26 June, 10 July and 11 July: the upper dust layer (a), the mixed aerosol layer (b) and the lower marine aerosol layer (c). Mean difference $\mu$, standard deviation of the difference $\sigma$, relative standard deviation (RSD) of the difference with respect to the mean of backscatter coefficient measured by POLIS and number of data points are given for each layer.

by two reasons: the representativeness error caused by the higher variability of the boundary layer and a larger extinction estimation uncertainty caused by the accumulated error in the previous two layers. As was explained in Sect. 4.3, the extinction coefficient conversion factor of the mixed layer was probably overestimated due to the impossibility to separate the effect of the marine aerosol layer and the mixed layer. This can be an explanation for the higher bias observed in the boundary layer measurements.

In order to investigate the effect of the uncertainty of the conversion factor on the retrieved values, the backscatter coefficients, the extinction coefficients and the error distribu- 

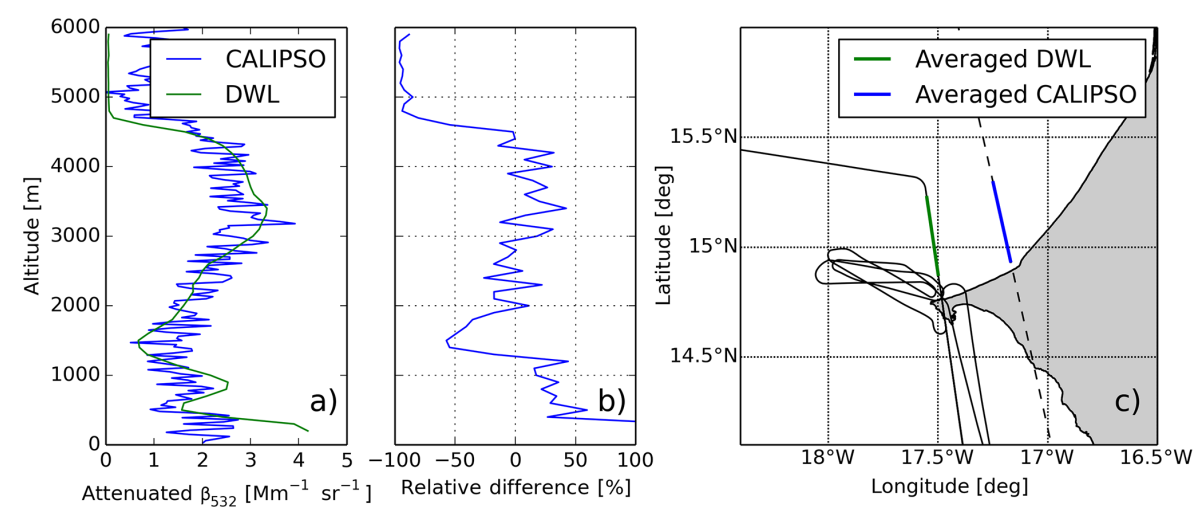

Figure 20. (a) Comparison of the averaged attenuated backscatter profiles retrieved from the DWL (green) and the corresponding averaged profile measured by CALIPSO (blue) during its overpass over Dakar region on 12 June. (b) Relative difference between the backscatter profiles retrieved from the DWL and the corresponding profile measured by CALIPSO as function of the altitude. (c) DLR Falcon (black, solid) and CALIPSO (black, dashed) tracks, together with the averaged sections (green for the DWL and blue for CALIPSO).

tions were recalculated using conversion factors $20 \%$ higher and $20 \%$ lower than the values estimated in Sect. 4.3 (Table 4).

It can be seen from Table 4 that the estimated conversion factors are of the right magnitude considering that a change of $\pm 20 \%$ generally increases the error of the retrieved backscatter coefficient.

\subsection{Validation with CALIPSO}

In order to perform an independent validation, the proposed method was applied to retrieve the attenuated backscatter coefficients (Eq. 20) for the flight on 12 June (Fig. 20a). During that flight, the DLR Falcon and the CALIPSO satellite performed simultaneous measurements on similar tracks (Fig. 20c). The aerosol layer used in this case consisted of one layer corresponding to Saharan dust and the corresponding calibration constant (Table 3 ) was used. The retrieved attenuated backscatter coefficient profile was compared with the corresponding CALIPSO attenuated backscatter profile (Level 1 data product).

As the measurements were performed during day, the attenuated backscatter profile retrieved from CALIPSO presents high levels of noise. Nevertheless, the comparison shows a good quantitative agreement between the CALIPSO and the DWL profiles (Fig. 20b) for altitudes between 500 and $4500 \mathrm{~m}$. The discrepancy observed in the boundary layer can be explained, as was mentioned before, by its higher variability. However, the difference observed for altitudes higher than $4500 \mathrm{~m}$ can be explained by the lack of DWL signal due to the very low aerosol concentrations.

\section{Summary and conclusions}

A new technique for the calibration of coherent DWL intensity to obtain backscatter and extinction coefficient was pre- sented and the derived results were validated with groundbased and satellite lidar measurements. The comparisons show good agreement between the coherent DWL operating at $2 \mu \mathrm{m}$ and the ground-based aerosol lidar working at $532 \mathrm{~nm}$, with a discrepancy lower than $20 \%$ in most of the cases.

The presented method can be applied to other lidar systems for which the molecular return intensity is too low to be used as reference for calibration. Although in the case of airborne systems the extinction corresponding to the first $500 \mathrm{~m}$ can be normally neglected, for ground-based systems it has to be determined and its influence corrected before the method can be applied.

The requirement of a ground-based aerosol lidar does not represent a serious limitation in the method's range of application considering that they are usually deployed during aerosol characterization campaigns.

In further studies, the use of the sea surface return intensity measured with the airborne DWL will be tested as complementary calibration and monitoring of the stability of the calibration constants.

Auxiliary lidar measurements and modeling of aerosol optical properties based on airborne in situ measurements (Gasteiger et al., 2011) can be used instead of sun photometer measurements to determine the extinction coefficient conversion factor corresponding to each aerosol layer with a higher accuracy and better aerosol type discrimination.

Acknowledgements. This work was funded by the Helmholtz Association under grant number VH-NG-606 (Helmholtz-HochschulNachwuchsforschergruppe AerCARE). The SALTRACE campaign was mainly funded by the Helmholtz Association, DLR, LMU and TROPOS. The SALTRACE test flights and the local flights on Cape Verde were funded through the DLR internal project VolcATS (Volcanic ash impact on the Air Transport System). CALIOP/CALIPSO data sets were obtained through the EOSDIS 
website (https://earthdata.nasa.gov/). The sun photometer work leading to these results has received funding from the European Union Seventh Framework Programme (FP7/2007-2013) under grant agreement nr. 262254 [ACTRIS]. We thank the AERONET teams at GSFC, LOA and UVA for their support.

The article processing charges for this open-access

publication were covered by a Research

Centre of the Helmholtz Association.

Edited by: U. Wandinger

\section{References}

Ansmann, A. and Müller, D.: Lidar and Atmospheric Aerosol Particles, in: Lidar, edited by: Weitkamp, C., Springer, New York, 105-141, 2005.

Ansmann, A., Wandinger, U., Riebesell, M., Weitkamp, C., and Michaelis, W.: Independent measurement of extinction and backscatter profiles in cirrus clouds by using a combined Raman elastic-backscatter lidar, Appl. Optics, 31, 7113-7113, 1992.

Ansmann, A., Petzold, A., Kandler, K., Tegen, I., Wendisch, M., Müller, D., Weinzierl, B., Müller, T., and Heintzenberg, J.: Saharan Mineral Dust Experiments SAMUM-1 and SAMUM-2: What have we learned?, Tellus B, 63, 403-429, 2011.

Böckmann, C., Wandinger, U., Ansmann, A., Bösenberg, J., Amiridis, V., Boselli, A., Delaval, A., De Tomasi, F., Frioud, M., Grigorov, I., Hågård, A., Horvat, M., Iarlori, M., Komguem, L., Kreipl, S., Larchevêque, G., Matthias, V., Papayannis, A., Pappalardo, G., Rocadenbosch, F., Rodrigues, J., Schneider, J., Shcherbakov, V., and Wiegner, M.: Aerosol lidar inter- comparison in the framework of the EARLINET project: Part II - Aerosol backscatter algo- rithms, Appl. Optics, 43, 977-989, 2004.

Bou Karam, D., Flamant, C., Knippertz, P., Reitebuch, O., Pelon, J., Chong, M., and Dabas, A.: Dust emissions over the Sahel associated with the West African monsoon intertropical discontinuity region: A representative case-study, Q. J. Roy. Meteor. Soc., 134, 621-634, 2008.

Bufton, J. L., Hoge, F. E., and Swift, R. N.: Airborne measurements of laser backscatter from the ocean surface, Appl. Optics, 22, 2603-2618, 1983.

Cutten, D. R., Rothermel, J., Jarzembski, M. A., Hardesty, R. M., Howell, J. N., Tratt, D. M., and Srivastava, V.: Radiometric calibration of an airborne $\mathrm{CO}_{2}$ pulsed Doppler lidar with a natural earth surface, Appl. Optics, 41, 3530-3537, 2002.

Eck, T. F., Holben, B. N., Reid, J. S., Dubovik, O., Smirnov, A., O'Neill, N. T., and Slutsker, I.: Wavelength dependence of the optical depth of biomass burning, urban, and desert dust aerosols, J. Geophys. Res., 104, 31333-31349, 1999.

Fernald, F. G.: Analysis of atmospheric lidar observations: some comments, Appl. Optics, 23, 652-653, 1984.

Frehlich, R. G. and Kavaya, M. J.: Coherent laser radar performance for general atmospheric refractive turbulence, Appl. Optics, 30, 5325-5352, 1991.

Freudenthaler, V., Esselborn, M., Wiegner, M., Heese, B., Tesche, M., Ansmann, A., Müller, D., Althause, D., Wirth, M., Fix, A., Ehret, G., Knippertz, P., Toledano, C., Gasteiger, J., Garhammer, M., and Seefeldner, M.: Depolarization ratio profiing at several wavelengths in pure Saharan dust during SAMUM 2006, Tellus B, 61, 165-179, 2009.

Freudenthaler, V., Seefeldner, M., Groß, S., and Wandinger, U.: Accuracy of linear depolarisation ratios in clean air ranges measured with POLIS-6 at 355 and $532 \mathrm{~nm}$, Proceeding of 27. International Laser Radar Conference, 5-10 July 2015, New York, 2015.

Gasteiger, J., Wiegner, M., Groß, S., Freudenthaler, V., Toledano, C., Tesche, M., and Kandler, K.: Modelling lidar-relevant optical properties of complex mineral dust aerosols, Tellus B, 63, 725741,2011

Groß, S., Esselborn, M., Weinzierl, B., Wirth, M., Fix, A., and Petzold, A.: Aerosol classification by airborne high spectral resolution lidar observations, Atmos. Chem. Phys., 13, 2487-2505, doi:10.5194/acp-13-2487-2013, 2013.

Heintzenberg, J.: The SAMUM-1 experiment over Southern Morocco: Overview and introduction, Tellus Series B, 61, 2-11, 2009.

Henderson, S. W., Suni, P. J. M., Hale, C. P., Hannon, S. M., Magee, J. R., Bruns, D. L., and Yuen, E. H.: Coherent laser radar at $2 \mu \mathrm{m}$ using solid-state lasers, IEEE T. Geosci. Remote, 31.1, 4-15, doi:10.1109/36.210439, 1993.

Henderson, S. W., Gatt, P., Rees, D., and Huffaker, R. M.: Wind Lidar, in: Laser Remote Sensing, edited by: Fujii, T. and Fukuchi, T., CRC Press, Boca Raton, 469-722, 2005.

Hinds, W. C.: Aerosol Technology: Properties, Behaviour and Measurement of Airborne Particles, John Wiley \& Sons, Inc., New York, 304-305, 1999.

Käsler, Y., Rahm, S., Simmet, R., and Kühn, M.: Wake measurements of a multi-MW wind turbine with coherent long-range pulsed doppler wind lidar, J. Atmos. Ocean. Tech., 27, 15291532, 2010.

King, M. D. and Byrne, D. M.: A Method for Inferring Total Ozone Content from the Spectral Variation of Total Optical Depth Obtained with a Solar Radiometer, J. Atmos. Sci., 33, 2242-2251, 1976.

Klett, J. D.: Lidar inversion with variable backscatter/extinction ratios, Appl. Optics, 24, 1638-1643, 1985.

Köpp, F., Rahm, S., and Smalikho, I.: Characterization of Aircraft Wake Vortices by $2-\mu \mathrm{m}$ Pulsed Doppler Lidar, J. Atmos. Ocean. Tech., 21, 194-206, 2004.

Li, Z., Lemmerz, C., Paffrath, U., Reitebuch, O., and Witschas, B.: Airborne Doppler Lidar Investigation of Sea Surface Reflectance at a 355-nm Ultraviolet Wavelength, J. Atmos. Ocean. Tech., 27 , 693-704, 2010.

Mahowald, N. M., Baker, A. R., Bergametti, G., Brooks, N., Duce, R. A., Jickells, T. D., Kubilay, N., Prospero, J. M., and Tegen, I.: Atmospheric global dust cycle and iron inputs to the ocean, Global Biogeochem. Cy., 19, 1-15, 2005.

Menzies, R. T. and Tratt, D. M.: Airborne $\mathrm{CO}_{2}$ coherent lidar for measurements of atmospheric aerosol and cloud backscatter, Appl. Optics, 33, 5698-5711, 1994.

O'Connor, E. J., Illingworth, A. J., and Hogan, R. J.: A technique for autocalibration of cloud lidar, J. Atmos. Ocean. Tech., 21, 777-786, 2004.

O’Neill, N. T., Eck, T. F., Reid, J. S., Smirnov, A., and Pancrati, O.: Coarse mode optical information retrievable using ultraviolet to short-wave infrared Sun photometry: Application to United Arab Emirates Unified Aerosol Experiment data, J. Geophys. Res., 113, D05212, doi:10.1029/2007JD009052, 2008. 
Prospero, J. M.: Long-range transport of mineral dust in the global atmosphere: Impact of African dust on the environment of the southeastern United States, P. Natl. Acad. Sci. USA., 96, 33963403, 1999.

Reitebuch, O.: Wind Lidar for Atmospheric Research, in: Atmospheric Physics, edited by: Schumann, U., Springer, Berlin Heidelberg, 487-507, 2012.

Reitebuch, O., Werner, C., Leike, I., Delville, P., Flamant, P. H., Cress, A., and Engelbart, D.: Experimental validation of wind profiling performed by the airbone $10-\mu \mathrm{m}$ heterodyne Doppler Lidar WIND, J. Atmos. Ocean. Tech., 18, 1331-1344, 2001.

Schumann, U., Weinzierl, B., Reitebuch, O., Schlager, H., Minikin, A., Forster, C., Baumann, R., Sailer, T., Graf, K., Mannstein, H., Voigt, C., Rahm, S., Simmet, R., Scheibe, M., Lichtenstern, M., Stock, P., Rüba, H., Schäuble, D., Tafferner, A., Rautenhaus, M., Gerz, T., Ziereis, H., Krautstrunk, M., Mallaun, C., Gayet, J.F., Lieke, K., Kandler, K., Ebert, M., Weinbruch, S., Stohl, A., Gasteiger, J., Groß, S., Freudenthaler, V., Wiegner, M., Ansmann, A., Tesche, M., Olafsson, H., and Sturm, K.: Airborne observations of the Eyjafjalla volcano ash cloud over Europe during air space closure in April and May 2010, Atmos. Chem. Phys., 11, 2245-2279, doi:10.5194/acp-11-2245-2011, 2011.

Seifert, P., Ansmann, A., Mattis, I., Wandinger, U., Tesche, M., Engelmann, R., Müller, D., Pérez, C., and Haustein, K.: Saharan dust and heterogeneous ice formation: Eleven years of cloud observations at a central European EARLINET site, J. Geophys. Res., 115, D20201, doi:10.1029/2009JD013222, 2010.
Smalikho, I.: Techniques of wind vector estimation from data measured with a scanning coherent Doppler Lidar, J. Atmos. Ocean. Tech., 20, 276-291, 2003.

Sonnenschein, C. M. and Horrigan, F. A.: Signal-to-Noise Relationships for Coaxial Systems that Heterodyne Backscatter from the Atmosphere, Appl. Optics, 10, 1600-1604, 1971.

Toledano, C., Wiegner, M., Groß, S., Freudenthaler, V., Gasteiger, J., Müller, D., Müller, T., Schladitz, A., Weinzierl, B., Torres, B., and O'Neill, N. T.: Optical properties of aerosol mixtures derived from sun-sky radiometry during SAMUM-2, Tellus Series B, 63, 635-648, 2011.

Weinzierl, B., Sauer, D., Minikin, A., Reitebuch, O., Dahlkötter, F., Mayer, B., Emde, C., Tegen, I., Gasteiger, J., Petzold, A., Veira, A., Kueppers, U., and Schumann, U.: On the visibility of airborne volcanic ash and mineral dust from the pilot's perspective in flight, J. Phys. Chem. Earth, 45, 87-102, 2012.

Weissmann, M., Busen, R., Dörnbrack, A., Rahm, S., and Reitebuch, O.: Targeted observations with an airborne wind lidar, J. Atmos. Ocean. Tech., 22, 1706-1719, 2005. 